\title{
Global Aspects of pacC Regulation of Pathogenicity Genes in Colletotrichum gloeosporioides as Revealed by Transcriptome Analysis
}

\author{
Noam Alkan, ${ }^{1}$ Xiangchun Meng, ${ }^{2,3}$ Gilgi Friedlander, ${ }^{1}$ Eli Reuveni, ${ }^{1}$ Serenella Sukno, ${ }^{4}$ Amir Sherman, ${ }^{5}$ \\ Michael Thon, ${ }^{4}$ Robert Fluhr, ${ }^{1}$ and Dov Prusky ${ }^{2}$ \\ ${ }^{1}$ Department of Plant Sciences, Weizmann Institute of Science, Rehovot, 76100, Israel; ${ }^{2}$ Department of Postharvest Science \\ of Fresh Produce, Agricultural Research Organization, the Volcani Center, Bet Dagan 50250, Israel; ${ }^{3}$ Fruit Tree Research \\ Institute, Guangdong Academy of Agricultural Sciences, Guangzhou, 510640, China; ${ }^{4}$ Centro Hispanoluso de Investigaciones \\ Agrarias (CIALE), Department of Microbiology and Genetics, University of Salamanca, Villamayor 37185, Spain; ${ }^{5}$ Genomic \\ Unit, Plant Sciences Institute, Agricultural Research Organization, the Volcani Center, Bet Dagan 50250, Israel
}

Submitted 19 March 2013. Accepted 13 July 2013.

Colletotrichum gloeosporioides alkalinizes its surroundings during colonization of host tissue. The transcription factor pacC is a regulator of $\mathrm{pH}-c o n t r o l l e d$ genes and is essential for successful colonization. We present here the sequence assembly of the Colletotrichum fruit pathogen and use it to explore the global regulation of pathogenicity by ambient $\mathrm{pH}$. The assembled genome size was $54 \mathrm{Mb}$, encoding 18,456 genes. Transcriptomes of the wild type and $\Delta p a c C$ mutant were established by RNA-seq and explored for their global pH-dependent gene regulation. The analysis showed that pacC upregulates 478 genes and downregulates 483 genes, comprising $5 \%$ of the fungal genome, including transporters, antioxidants, and cell-wall-degrading enzymes. Interestingly, gene families with similar functionality are both up- and downregulated by pacC. Global analysis of secreted genes showed significant pacC activation of degradative enzymes at alkaline $\mathrm{pH}$ and during fruit infection. Select genes from alkalizing-type pathogen C. gloeosporioides and from acidifying-type pathogen Sclerotinia sclerotiorum were verified by quantitative reversetranscription polymerase chain reaction analysis at different pH values. Knock out of several pacC-activated genes confirmed their involvement in pathogenic colonization of alkalinized surroundings. The results suggest a global regulation by pacC of key pathogenicity genes during $\mathrm{pH}$ change in alkalinizing and acidifying pathogens.

Genus Colletotrichum is distributed worldwide and species in this family are important agents in causing fruit rot both in the field and postharvest (Prusky 1996; Wharton and DiéguezUribeondo 2004). Colletotrichum gloeosporioides displays sequential quiescent and active necrotrophic-infection strategies to promote colonization. During quiescence, the fungus remains dormant for weeks until fruit ripening; the switch from quies-

N. Alkan and X. Meng jointly contributed to this article.

Corresponding author: N. Alkan; Telephone: +972-3-9683605; Fax: +9723-9683622; E-mail: noamal@agri.gov.il

* The $e$-Xtra logo stands for "electronic extra" and indicates that three supplementary figures and seven supplementary tables are published online. Also, Figure 1 appears on color online.

(C) 2013 The American Phytopathological Society cence to necrotrophy is dependent on fruit maturation (Prusky et al. 2010). During its appressorial penetration and necrotrophic development, $C$. gloeosporioides is known to alkalinize the ambient $\mathrm{pH}$ by massive secretion of ammonia (Alkan et al. 2008; Miyara et al. 2010; Prusky et al. 2001; Shnaiderman et al. 2013), increasing the local $\mathrm{pH}$ by $4 \mathrm{pH}$ units from $\mathrm{pH} 4.0$ to 8.0 (Alkan et al. 2008; Prusky and Yakoby 2003). In a similar fashion, C. higginsianum, C. graminicola, Alternaria alternata, and Fusarium oxysporum alkalinize their surroundings by ammonia secretion (Eshel et al. 2002; Miyara et al. 2012; O'Connell et al. 2012). Ammonia secretion is known to activate host-programed cell death (Alkan et al. 2008, 2009, $2012 \mathrm{~b}$ ), and ammonia-driven alkalization is thought to optimize pathogenicity for necrotrophic colonization (Alkan et al. 2008, 2009; Miyara et al. 2008). Environmental alkalization during infection is accompanied by the induction of pathogenicity factors, as was reported for pectate lyase (PelB) in $C$. gloeosporioides (Yakoby et al. 2000); polygalacturonase (PG1 and PG5) in F. oxysporum (Caracuel et al. 2003b), and endoglucanases in A. alternata (Eshel et al. 2002).

In filamentous fungi, the expression of genes in alkaline conditions is governed by a complex ambient-pH-sensing, signaltransduction pathway consisting of six phenylalanine ammonia lyase gene products that cleave the zinc finger transcription factor pacC at alkaline $\mathrm{pH}$ and was characterized in Aspergillus nidulans (Andersen et al. 2009; Galindo et al. 2012; NegreteUrtasun et al. 1999; Penalva and Arst 2002, 2004; Penalva et al. 2008). Thus, under alkaline $\mathrm{pH}$ conditions, pacC serves as a positive regulator promoting transcription of alkaline-expressed genes while it is suggested to simultaneously repress acidexpressed genes (Arst and Penalva 2003; Tilburn et al. 1995). For example, PelB, a secreted cell-wall-degrading enzyme (CWDE), is controlled by the transcription factor pacC under alkalinizing conditions (Miyara et al. 2008).

The promoter regions of alkaline-expressed genes controlled by pacC contain multiple copies of the transcription factor binding site 5'-GCCARG 3' (Espeso et al. 1997; Miyara et al. 2010). Importantly, loss-of-function mutants of $\triangle p a c C$ result in an acid-mimicking phenotype even in alkaline conditions (AbuQamar et al. 2006; Arst et al. 1994; Caddick et al. 1986; Diaz et al. 2002; Espeso and Arst 2000; Orejas et al. 1995; Tilburn et al. 1995). Thus, the mutant behaves as if it is in an environment of lower ambient $\mathrm{pH}$ with increased expression of acid-expressed genes and decreased expression of alkaline- 
expressed genes. Indeed, $\Delta p a c C$ mutants of $C$. gloeosporioides, C. acutatum, F. oxysporum, and Sclerotinia sclerotiorum show reduced virulence (Caracuel et al. 2003a; Rollins 2003; Miyara et al. 2008; You et al. 2007).

Our hypothesis is that the impact of pacC on virulence is due to its regulation of pathogenicity genes under alkalizing $\mathrm{pH}$ conditions. Thus, in the present work, we analyzed global aspects of pacC regulation by transcriptome and functional analysis. Based on high-throughput RNA sequencing, we demonstrate that pacC upregulates 478 and downregulates 483 genes, some of which appear to be involved in the development of necrotrophic pathogenicity. The regulated genes include transporters and antioxidants that function to maintain cellular homeostasis and control the secretion of pathogenicity factors. Functional analysis by gene knock-out in $C$. gloeosporioides of a number of genes expressed at alkaline $\mathrm{pH}$ confirms their involvement in pathogenicity. Thus, pacC is a key factor in the regulation of many genes that contribute to $C$. gloeosporioides pathogenicity. We also provide evidence that, in acidifying-type fungi as well, pacC-regulated genes appear to play a similar role in the control of pathogenicity.

\section{RESULTS}

Comparison of Colletotrichum genomes.

The genome of the postharvest fruit pathogen $C$. gloeosporioides $\mathrm{Cg}$-14 isolate was sequenced to a depth of approximately 10x using 454 GS FLX Titanium technology. The sequence reads were assembled using the GS De Novo Assembler software (454 Corp.) yielding 4,907 contigs larger than $500 \mathrm{bp}$, with an average size of $24.5 \mathrm{~kb}$ and $53 \%$ GC content (GenBank accession number SUB133583). These contigs have a total length of $54.5 \mathrm{Mb}$, which is similar to the recently published genomes of $C$. graminicola $(57.4 \mathrm{Mb})$ and $C$. higginsianum (53.4 Mb) (Table 1) (O'Connell et al. 2012). Two other strains of $C$. gloeosporioides that were isolated from leaves and stem were recently released (Joint Genome Institute) (Gan et al. 2013). Those genome sizes are 58.8 and $55.6 \mathrm{Mb}$, respectively (Table 1).

The GeneMark-ES algorithm predicted 18,456 protein-coding gene models in the $C$. gloeosporioides genome. This number of genes is 14 to $53 \%$ more than the number of genes predicted in the $C$. higginsianum and $C$. graminicola genomes $(16,172$ and 12,006, respectively) (O'Connell et al. 2012). The RNASeq transcriptome analysis of $C$. graminicola and C. higginsianum yielded 14,972 and 10,812 transcripts, respectively, compared with 16,603 in the transcriptome of $C$. gloeosporioides (Table 1). Thus, the major variance detected is in the number of transcripts, with the highest number of transcripts in $C$. gloeosporioides. In all cases, the genomes displayed 8 to $11 \%$ more predicted genes than that revealed by transcriptome analysis. This discrepancy is likely due to the difficulty in detecting genes that are expressed at low levels or undergo stagespecific expression. Additionally, similar numbers of secreted

Table 1. Genome comparisons in the genus Colletotrichum

\begin{tabular}{|c|c|c|c|c|c|c|}
\hline Species $^{a}$ & Genome size (Mb) & Predicted proteins & In vivo transcript & Secretome & GC $(\%)$ & Reference \\
\hline C. gloeosporioides (Cg-14) & 54 & 18,456 & 16,603 & 1,955 & 53 & Present work \\
\hline C. gloeosporioides (Musae 23) & 58.8 & 18,975 & $\ldots$ & $\ldots$ & $\ldots$ & $\ldots$ \\
\hline C. gloeosporioides (Nara gc5) & 55.6 & 15,469 & $\ldots$ & 2,042 & 53.6 & Gan et al. 2012 \\
\hline C. orbiculare & 88.3 & 13,479 & $\ldots$ & 1,557 & 37.5 & $\ldots$ \\
\hline C. higginsianum & 53.4 & 16,172 & 14,972 & 2,142 & 49.1 & O'Connell et al. 2012 \\
\hline C. graminicola & 57.4 & 12,006 & 10,812 & 1,650 & 55.1 & $\ldots$ \\
\hline
\end{tabular}

a Six genomes were compared: Colletotrichum gloeosporioides (Cg-14); isolated form avocado fruit; C. gloeosporioides (Joint Genome Institute), an endophyte obtained from oak seedling; $C$. gloeosporioides (Nara gc5) (Gan et al. 2012), isolated from strawberry leaves; $C$. orbiculare (Gan et al. 2012); C. higginsianum (O'Connell et al. 2012); and C. graminicola (O'Connell et al. 2012). Genome size, number of predicted proteins, total in vivo transcripts number identified by Cufflink transcriptome analysis, secreted proteins, and average GC (\%) are shown. Expressed transcripts of $C$. higginsianum and $C$. graminicola are the combined expression from the transcriptomes of three different stages of colonization stages, including germination, biotrophic, and necrotrophic stages.

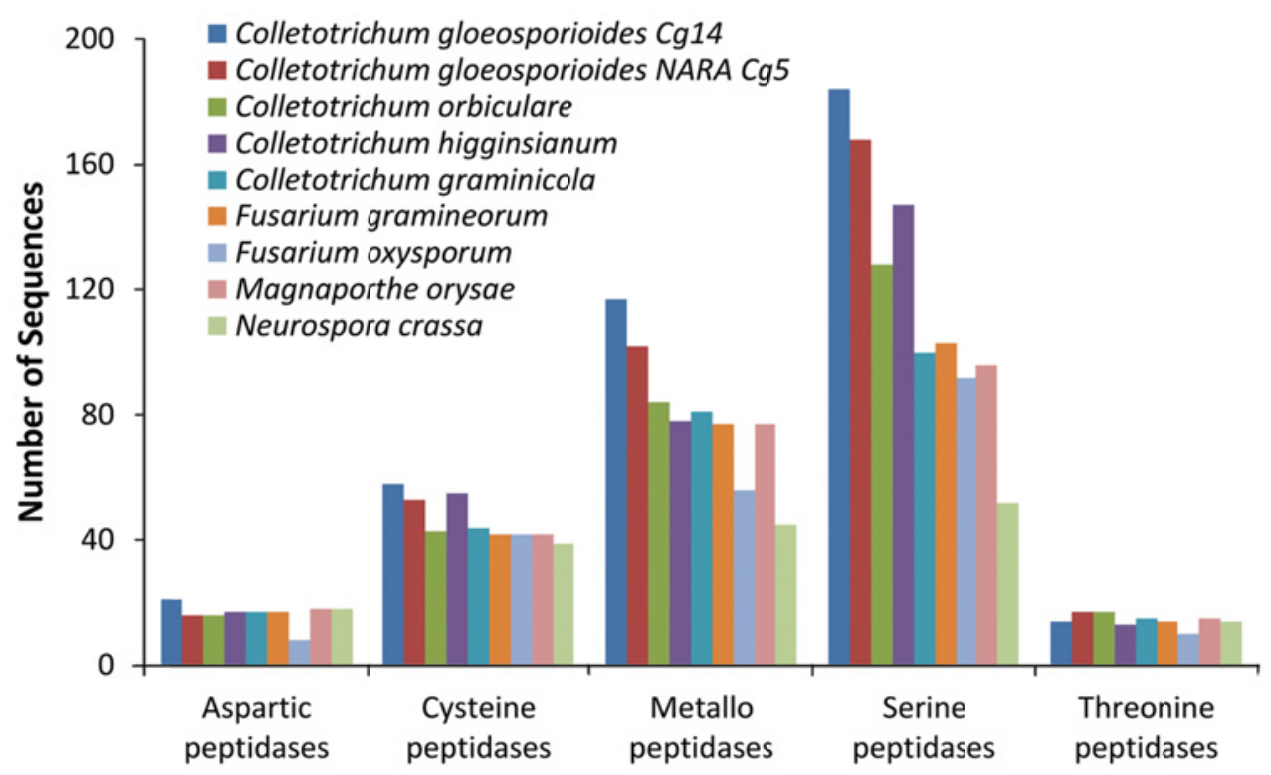

Fig. 1. Proteases in Colletotrichum spp. and other fungi. Number of predicted proteases encoded by the Colletotrichum gloeosporioides genomes in comparison with other fungi, based on MCL clustering of predicted protein sequences of the different genomes. 
proteins were detected by in silico analysis in most Colletotrichum spp., with lower numbers of secreted proteins in $C$. graminicola and $C$. orbiculare (Table 1). Comparison of the numbers of peptidases in fungal genomes revealed that most Colletotrichum spp. have more serine and cysteine peptidase than other fungal species tested. Furthermore, C. gloeosporioides genomes that have a wider host range possess more peptidase than other Colletotrichum spp. (Fig. 1).

To identify conserved regions showing co-localization of genes on chromosomes (synteny) within Colletotrichum spp., we aligned the $C$. gloeosporioides genome sequence to the genome of $C$. graminicola using symap 4.0 (Soderlund et al. 2006). Symap identified 9,482 alignments (anchors) between the two species, representing $30 \%$ of the C. gloeosporioides genome; this value is similar to the $34 \%$ synteny reported between $C$. higginsianum and $C$. graminicola (O'Connell et al. 2012). The anchored assembly enabled identification of 340 syntenic blocks between the two species (Supplementary Fig. S1). In all, $90 \%$ of C. gloeosporioides anchors fall within gene models in both species showing higher conservation in coding genes than in the noncoding sequence of the genome.

The large number of contigs in $C$. gloeosporioides NARA gc5 genome assembly as well as in the $C$. gloeosporioides $\mathrm{Cg}$ 14 genome prevented a detailed analysis of conserved synteny. Instead, we aligned the two C. gloeosporioides genomes of NARA gc5 and Cg-14 using Mauve analysis (Darling et al. 2010). The Mauve analysis resulted in 19,043 anchor alignments covering $89.4 \%$ of the NARA gc5 genome sequence. The remaining $10.4 \%$ of the NARA gc5 genome that was not aligned to $\mathrm{Cg}-14$ could be missing from the $\mathrm{Cg}-14$ genome or it could be too divergent to be aligned by the Mauve algorithm.

\section{Transcriptome analysis of $C$. gloeosporioides reveals genome-wide pacC-dependent regulation.}

In order to characterize global aspects of $\mathrm{pH}$-regulated genes that are important for environmental fitness and pathogenicity, we characterized the pacC-regulated transcriptome. To this end, RNA-seq was applied to the $C$. gloeosporioides wild type (WT) and a reduced-pathogenicity $\Delta p a c C$ mutant (Miyara et al. 2008) grown at $\mathrm{pH} 7.0$ for different periods post-culture inoculation (discussed below). The $\triangle p a c C$ strain behaved as an acid-mimic mutant, because it misregulated $\mathrm{pH}$-controlled genes (AbuQamar et al. 2006; Arst et al. 1994; Caddick et al. 1986; Diaz et al. 2002; Espeso and Arst 2000; Orejas et al. 1995; Tilburn et al. 1995). Thus, genes that are upregulated in the WT compared with the $\Delta p a c C$ mutant at alkaline condition (at $\mathrm{pH}$ 7.0) can be considered to be alkaline expressed. Alternatively, genes that are downregulated in the WT compared with $\triangle p a c C$ mutant in those conditions can be considered to be acid expressed. To properly define transcriptional units, sequenced reads were compared with the GeneMark predicted transcripts. Regions with over $90 \%$ similarity between the predicted transcripts (from genome analysis) and the transcribed RNA established by RNA-seq analysis are presented in conversion Supplementary Table S1, showing the intron, exons, and transcript length. Functional annotation was carried out using Blast2GO software of the Cufflink-identified transcripts. The annotation includes enzyme code, InterPro annotation, and KEGG number maps (Supplementary Table S2). Transcripts that were differently regulated between the WT and $\Delta$ pacC mutants transcriptome were chosen if a significant twofold change in expression was detected. In this manner, 478 upregulated and 483 downregulated genes were detected representing together more than 5\% of the transcripts (Supplementary Tables S3 and S4). The up- and downregulation of genes is consistent with pacC acting as a gene activator and repressor during alkalization.
PacC up- and downregulated genes are alkaline- and acid-expressed and showed different induction kinetics.

To verify the transcriptome analysis and the hypothesis that comparison of WT and $\Delta$ pacC mutants grown at $\mathrm{pH} 7.0$ will reveal alkaline- and acid-expressed genes, several up- and downregulated genes were selected from the transcriptome data and examined by quantitative reverse-transcription polymerase chain reaction (RT-qPCR) for their relative expression at $\mathrm{pH} 4.0$ and 7.0. The genes shown in Figure 2 were further selected based on their importance in ammonia transport, ion transport for homeostasis maintenance, and CWDE for pathogenicity. These genes include ammonia exporter (AMET),
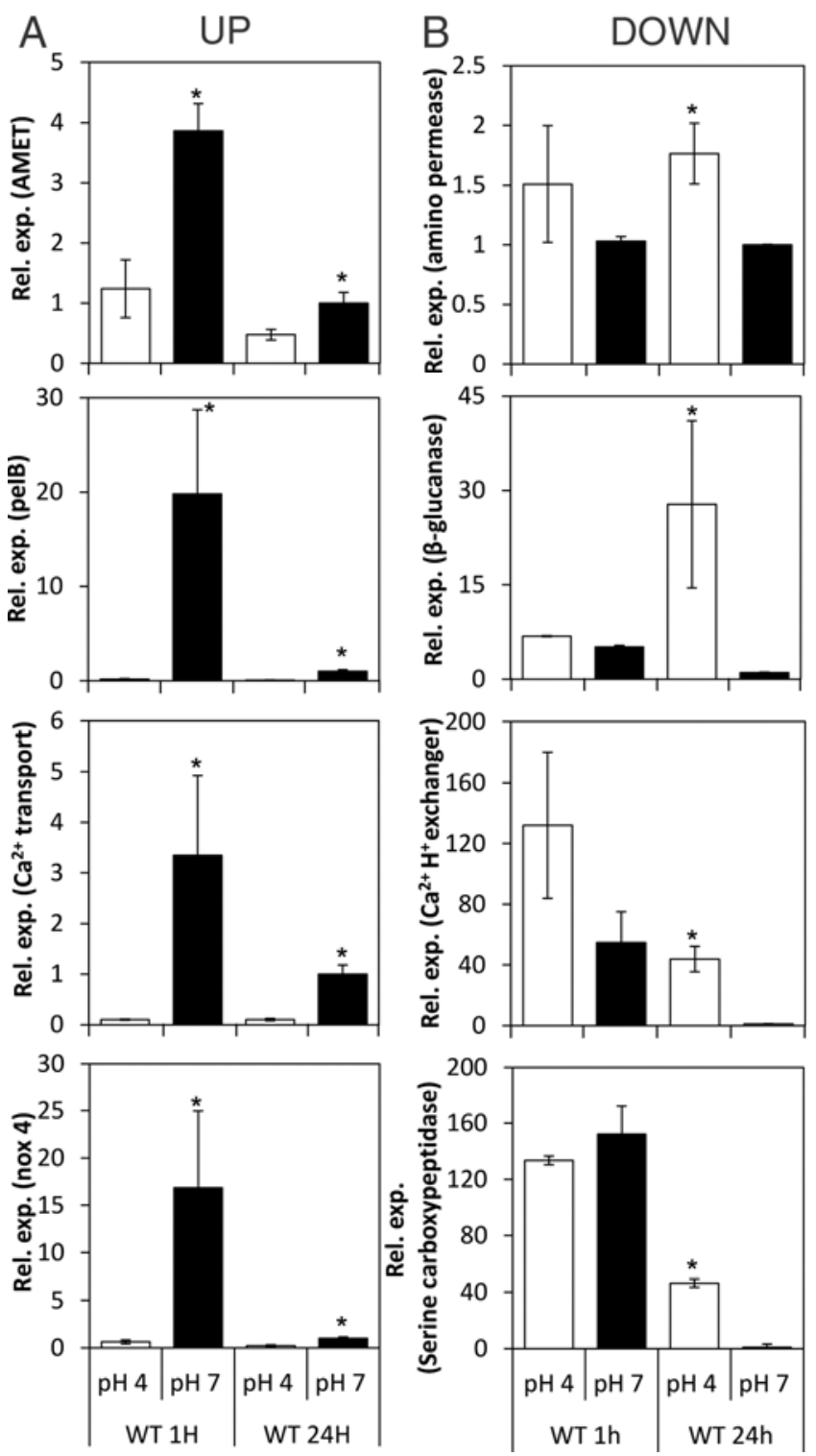

Fig. 2. Relative expression of Colletotrichum gloeosporioides wild-type (WT) genes determined by quantitative reverse-transcriptase polymerase chain reaction (RT-qPCR). C. gloeosporioides up- and downregulated genes selected from different Gene Ontology terms were measured 1 and $24 \mathrm{~h}$ after introducing cultures to $\mathrm{pH} 4.0$ or 7.0. Their relative expression was determined by RT-qPCR with an actin-related gene as reference gene. WT growth for $24 \mathrm{~h}$ at $\mathrm{pH} 7.0$ was assigned the relative number 1. A, Relative expression of pacC-upregulated genes AMET (TCONS_00010049), pelB (TCONS_00001544), Ca transporting ATPase (TCONS_00015152), and nox4 (TCONS_00008736). B, Relative expression of pacCdownregulated genes amino permease, (TCONS_00007335), $\beta$-glucanase (TCONS_00000095), Ca proton exchanger (TCONS_00010215), and serine carboxypeptidase (TCONS_00008162). 

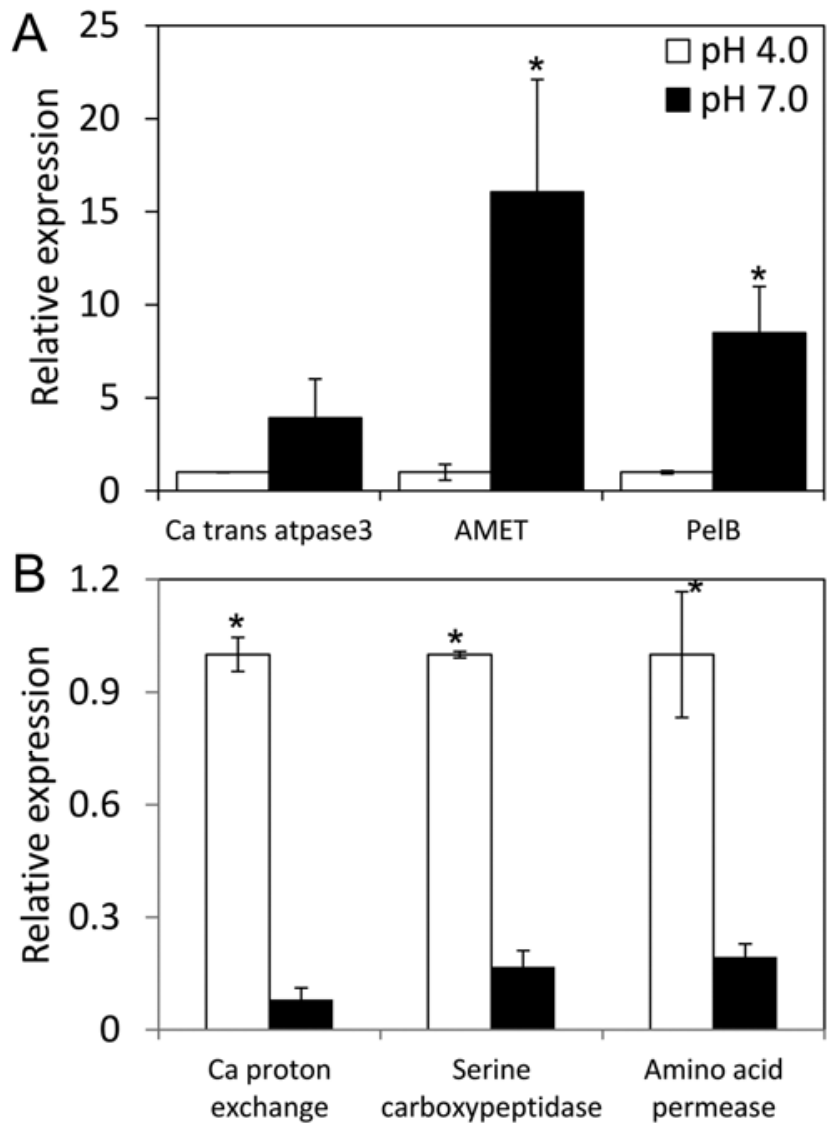

Fig. 3. Relative expression of Sclerotinia sclerotium wild-type (WT) genes. S. sclerotium up- and downregulated genes, representatives of different Gene Ontology terms were selected and their relative expression was measured $8 \mathrm{~h}$ after subculture at $\mathrm{pH} 4.0$ or 7.0. The relative expression was determined by quantitative reverse-transcriptase polymerase chain reaction with actin as reference gene. The WT grown for $8 \mathrm{~h}$ in pH 4.0 was assigned the relative number 1. A, Relative expressions of the pacC-upregulated genes pelB (SS1G_00238), Ca transporter ATPase3 (SS1G_06668), and AMET (SS1G_06601). B, Relative expressions of the pacC-downregulated genes calcium proton exchanger (SS1G_14108), serine carboxypeptidase (SS1G_13633), and amino acid permease (SS1G_10461). amino permease, $\mathrm{Ca}^{+2} / \mathrm{H}^{+}$exchanger, $\mathrm{Ca}^{+2}$ transporter, nox 4 , $\beta$-glucanase, PelB, and serine carboxypeptidase. Expression of the up- and downregulated transcripts, as established by RNAseq analysis of the $\Delta p a c C$ strain, were elevated or decreased in alkaline environments, respectively (Fig. 2). Thus the upregulated genes were alkaline-expressed genes and the downregulated genes were acid-expressed genes. Interestingly, RT-qPCR analysis showed that the alkaline-upregulated genes were elevated within $1 \mathrm{~h}$ after $\mathrm{pH}$ shift to $\mathrm{pH}$. 7.0. However, the expression of the acid-induced genes was relatively delayed and increased approximately $24 \mathrm{~h}$ later (Fig. 2). In addition, the RNA-seq results were examined for known $\mathrm{pH}$ regulation of alkaline and acid phosphatase-expressed genes (Dorn 1965). Indeed, alkaline phosphatase TCONS_00015964 was found to be upregulated whereas the acid phosphatase TCONS 00006263 and TCONS_00004441 is downregulated. These results validate the RNA-seq analysis and show that pacC upregulates alkaline-expressed genes and downregulates acidexpressed genes at alkaline condition.

\section{Conserved pacC regulation}

between $C$. gloeosporioides and $S$. sclerotiorum.

We examined whether pacC-regulated genes, identified in a pathogen that alkalinizes its ambient $\mathrm{pH}$ (e.g., C. gloeosporioides), are similar in fungi that acidify their surroundings. To this end, the set of best homologs to the $C$. gloeosporioides transcripts shown in Figure 2 were identified in S. sclerotiorum and examined under alkaline and acidified condition $(\mathrm{pH} 7.0$ and 4.0). Indeed, $8 \mathrm{~h}$ after introducing the fungus to $\mathrm{pH} 7.0$ or 4.0 , the expression of the predicted pacC-upregulated genes were elevated in $\mathrm{pH} 7.0$, whereas pacC-downregulated genes were highly expressed at $\mathrm{pH} 4.0$ (Fig. 3). This suggests that both alkalizing and acidifying fungi possess homologous genes of alkaline- and acid-expressed transcripts to cope with $\mathrm{pH}$ change.

Gene family sizes of pacC-regulated genes were examined in $C$. gloeosporioides in comparison with related families in other diverse fungi. To this end, upregulated transcripts of $C$. gloeosporioides were clustered together with those of $C$. graminicola, $C$. higginsianum, Neurospora crassa, A. nidulans, $S$. sclerotiorum, and Botrytis cinerea using the clustering software MCL. Selected representative clusters are presented in

Table 2. Fungal gene clusters ${ }^{\mathrm{a}}$

\begin{tabular}{|c|c|c|c|c|c|c|c|c|}
\hline \multirow[b]{2}{*}{ Function $^{b}$} & \multirow[b]{2}{*}{ Cluster $^{c}$} & \multicolumn{3}{|c|}{ Alkalizing } & \multicolumn{2}{|c|}{ Neutral } & \multicolumn{2}{|c|}{ Acidifying } \\
\hline & & C.gl & C.h & C.gr & N.c & A.n & S.s & B.c \\
\hline MFS transporter & 2 & 179 & 158 & 90 & 27 & 90 & 31 & 40 \\
\hline Sugar transporter & 4 & 127 & 111 & 70 & 32 & 96 & 47 & 63 \\
\hline Integral membrane protein & 5 & 126 & 110 & 81 & 28 & 62 & 42 & 55 \\
\hline Amino acid permease & 23 & 39 & 26 & 19 & 10 & 27 & 17 & 19 \\
\hline Calcium-translocating ATPase & 48 & 17 & 19 & 13 & 7 & 13 & 6 & 8 \\
\hline C6 zinc finger & 74 & 18 & 17 & 8 & 4 & 13 & 4 & 9 \\
\hline Isoflavone reductase & 92 & 22 & 17 & 11 & 3 & 7 & 3 & 5 \\
\hline Pectate lyase & 139 & 14 & 15 & 4 & 1 & 5 & 0 & 2 \\
\hline Glycosyl hydrolase & 172 & 9 & 8 & 7 & 6 & 5 & 11 & 11 \\
\hline Epimerase & 211 & 14 & 6 & 6 & 1 & 4 & 2 & 2 \\
\hline Endoglucanase & 214 & 5 & 4 & 3 & 4 & 2 & 3 & 3 \\
\hline Galactoside O-acetyltransferase & 231 & 9 & 5 & 4 & 3 & 5 & 3 & 2 \\
\hline GDSL-like lipase/acylhydrolase & 287 & 9 & 5 & 5 & 1 & 5 & 2 & 1 \\
\hline Serine carboxypeptidase & 384 & 6 & 3 & 3 & 1 & 1 & 3 & 5 \\
\hline Endoribonuclease L-PSP & 582 & 10 & 5 & 3 & 0 & 5 & 1 & 0 \\
\hline Amidase & 807 & 6 & 2 & 2 & 1 & 1 & 2 & 2 \\
\hline Amidohydrolase & 1,044 & 4 & 5 & 2 & 1 & 2 & 0 & 0 \\
\hline Chromo domain-containing & 5,383 & 7 & 2 & 1 & 0 & 0 & 0 & 0 \\
\hline
\end{tabular}

${ }^{\text {a } C o l l e t o t r i c h u m ~ g l o e o s p o r i o i d e s ~ p a c C ~ u p r e g u l a t e d ~ g e n e ~ c l u s t e r s ~(C . g l), ~ c o m p a r e d ~ w i t h ~ C . ~ h i g g i n s i a n u m ~(C . h), ~ C . ~ g r a m i n i c o l a ~(C . g r), ~ N e u r o s p o r a ~ c r a s s a ~}$ (N.c), Aspergillus nidulans (A.n), Sclerotinia sclerotiorum (S.s), and Botrytis cinerea (B.c)

${ }^{\mathrm{b}}$ Protein families were identified with the clustering program MCL. Functions of the proteins within each family were annotated using InterPro and BLAST searches. Selected clusters are presented.

c MCL Cluster ID. 
Table 2. The results show larger-sized gene families in C. gloeosporioides compared with other Colletotrichum spp., and larger gene families in fungi that alkalize their surroundings compared with fungi that acidify their ambient $\mathrm{pH}$. This observation is consistent with the finding that $C$. gloeosporioides has more predicted genes in general than other Colletotrichum spp. The complete comparative gene cluster analysis between fungal species for up- and downregulated sets of genes is presented in Supplementary Table S5.

\section{Members of the same functional family are differentially regulated by pacC.}

The Ontologizer program (Bauer et al. 2010) was used in order to identify groups of genes that are regulated in $C$. gloeosporioides by pacC. Many groups with similar functional activities appeared to be both up- and downregulated by pacC (Fig. 4). For example, CWDE that could contribute to fungal pathogenicity, transport activity and antioxidants were both up- and downregulated and could balance fungal redox and homeostasis in coping with extremes of $\mathrm{pH}$ (Fig. 4). When the "cellulase family" that belongs to the CWDE is examined in detail (Table 3 ), it was found to include 23 transcripts with putative cellulase activity (GO:0008810). Of these, seven were significantly upregulated while six transcripts were significantly downregulated. Similarly, of seven sulfate transport members (GO:0008272), three were upregulated genes and another three were downregulated by pacC (Table 3 ).

PacC controls secreted proteins with catabolic activity.

PacC regulates many CWDE and a pacC null mutant showed a major reduction in pathogenicity (Miyara et al. 2008). Because
CWDE are secreted enzymes, we further analyzed the overlap between pacC regulation and secreted proteins. To this end, we identified 1,955 putative secreted proteins in the $C$. gloeosporioides genome using WoLF PSORT applied to the GeneMark predicted transcripts (Horton et al. 2007). Of these, 870 transcripts had over $90 \%$ homology to transcripts identified by the Cufflink algorithm and, of them, 88 and 39 genes were found to overlap with pacC up- and downregulated genes, respectively (Fig. 5A). The degree of overlap between the secretome and the pacC-upregulated set was significantly more than expected (3.3-fold overrepresentation). This indicates that the secretome is enriched for pacC-regulated genes. Annotation of the pacC-regulated and secreted genes classified them into three main groups: cell wall catabolic, macromolecule catabolic, and proteolysis (Fig. 5B). Selected pacCupregulated secreted genes were analyzed on media at $\mathrm{pH}$. 7.0 and 4.0. The results confirmed elevated expression under alkaline condition (Fig. 6A). Because the natural fruit infection court is alkaline, RT-qPCR analysis of the same genes was carried out using infected avocado fruit tissue and compared with fungal growth in $\mathrm{M}_{3} \mathrm{~S}$ media ( $\mathrm{Tu}$ 1985) at $\mathrm{pH}$ 5.5. The results showed a significant enhancement in transcript expression. These results confirm the in vitro results and suggest that secreted pacC-regulated genes contribute to fungal pathogenicity at the necrotrophic stage (Fig. 6B).

The impact of pacC on fungal pathogenicity.

It has been reported that $\triangle p a c C$ mutants of $C$. gloeosporioides, $C$. acutatum, F. oxysporum, A. nidulans, and $S$. sclerotiorum are less virulent compared with the WT (Bignell et al. 2005; Caracuel et al. 2003a; Miyara et al. 2008; Rollins 2003;
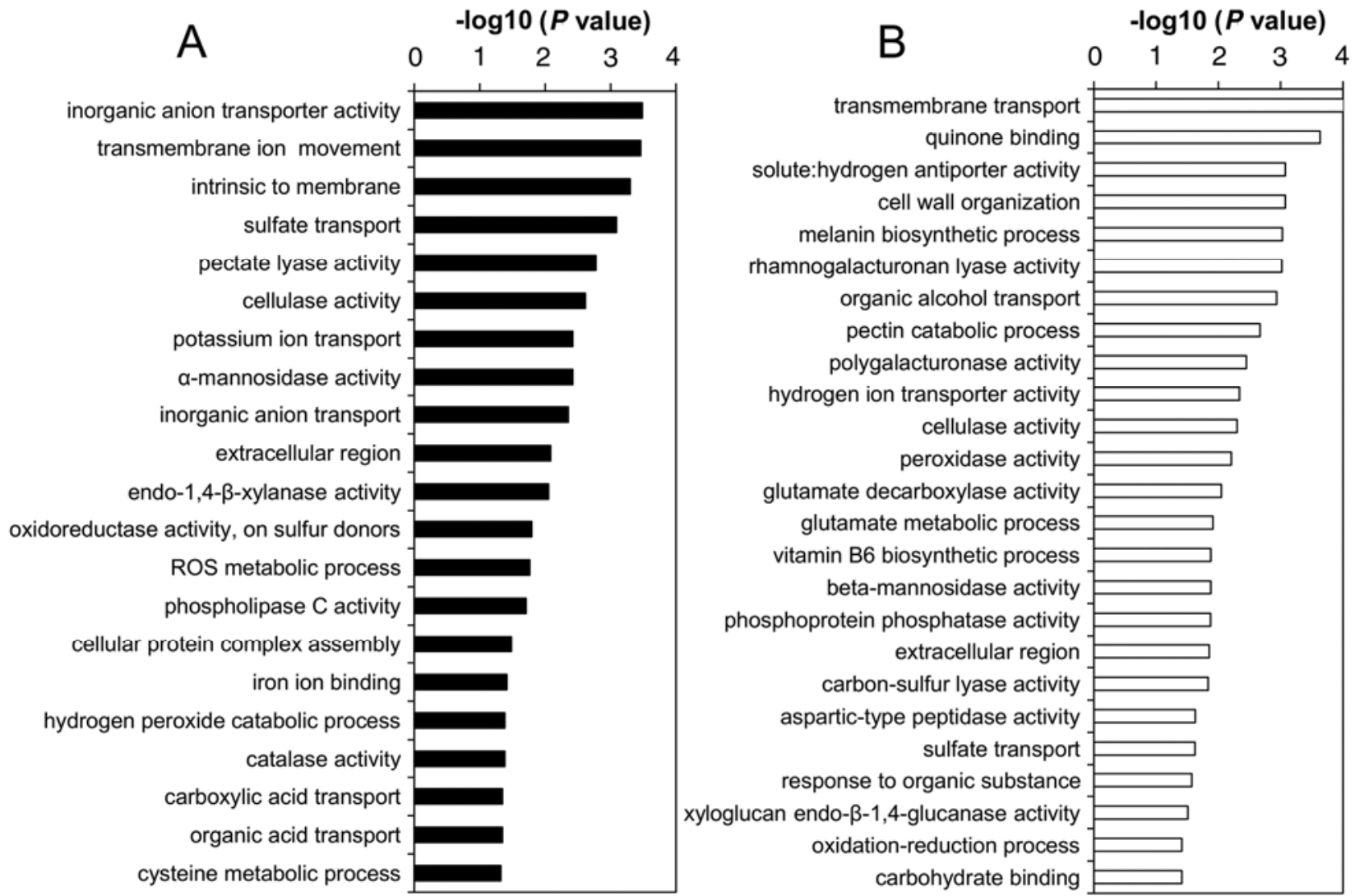

Fig. 4. Gene Ontology terms overrepresentation in Colletotrichum gloeosporioides pacC up- and downregulated genes. C. gloeosporioides pacC up- and downregulated genes that changed by twofold and had a significance q value of less than 0.05 were associated to GO terms. The GO overrepresentation analysis used Ontologizer software limited by Benjamini-Hochberg settings (Bauer et al. 2010). The topology-weighted analysis was with $P$ value lower than 0.05 . A, In total, 11,603 genes were in the population set, 478 of which were in the upregulated set, the significance presented as $-\log 10(P$ value $)$. B, In total, 11,603 genes were in the population set, 483 of which were in the downregulated set, the significance presented as $-\log 10(P$ value $)$. 
You et al. 2007). Because the elimination of pacC induces the misregulation of many genes, it raises the question of the importance, if any, of individual genes on pathogenicity. To assess this, we examined genes that impact $C$. gloeosporioides pathogenicity (Table 4). For example, $\Delta p e l B$, the secreted PelB (TCONS_00014224); $\Delta m e p B$, the ammonium permease (MEPB) (TCONS_00015558); _samet, the AMET (TCONS_ 00010049); and $\Delta$ chip6, the sterol glycosyl transferase (TCONS_00013643) all show significant reduced pathogenicity during necrotrophic colonization on avocado fruit (Kim et al. 2002; Miyara et al. 2012; Shnaiderman et al. 2013; Yakoby et al. 2001). They are also all significantly upregulated by pacC (Table 4). Interestingly, glutamate dehydrogenase (GDH) ( $\Delta g d h 2)$ (TCONS_00001112), a gene responsible for producing ammonia at acidic $\mathrm{pH}$, was found to be repressed by pacC and its deletion mutant has been shown to display reduced pathogenicity (Miyara et al. 2012).

Two other secreted pacC-controlled products were mutated by gene knock out through homological recombination of chitin deacetylase $(C D A)$ and aspartic protease $(A S P)$ (Table 4). The $\Delta c d a$ homologous recombination of 16 bases upstream of the ATG to 340 bases upstream of the stop codon with hygromycin-resistance gene was validated by PCR analysis of the 5'- and 3'-end PCR fragment with appropriate primer pairs (Fig. 7). Testing in vitro by RT-qPCR for $C D A$ gene expression in three $\Delta c d a$ mutant strains revealed elimination of $C D A$ ex- pression (Fig. 7). However, elimination of this gene expression did not play a significant role in pathogenicity on fruit (Supplementary Fig. S2). Because paralogs of CDA exist in the genome, its functionality may be redundant. This possibility was confirmed by the observation of two other CDA genes that had increased expression in the background of the $\Delta c d a$ mutant when compared with the WT and ectopic strains (Supplementary Fig. S3). The results suggest functional compensation in the $\Delta c d a$ mutant and only multiple knock down of the whole gene family may alter pathogenicity.

ASP (TCONS_00013084), a secreted putative ASP, showed significant activation by pacC and during necrotrophic colonization on avocado fruit. Knockout of ASP was achieved by homologous recombination with hygromycin-resistance gene insertion 384 bases downstream of the ATG to 442 bases upstream of the stop codon. The insertion was validated by PCR analysis of $5^{\prime}$ - and $3^{\prime}$-end PCR fragments with the appropriate primer pairs (Fig. 8). In addition, testing in vitro ASP gene expression in three $\Delta a s p$ mutant strains by RT-qPCR revealed no expression of transcripts (Fig. 8). Importantly, $\Delta a s p$ showed a significant reduction in pathogenicity during necrotrophic colonization on avocado fruit (Fig. 9; Table 4).

\section{Pathogenicity factors in acidifying fungi.}

PacC mutants of neutral and acidifying fungi such as $A$. nidulans and $S$. sclerotiorum are also less virulent compared with

Table 3. PacC regulation of cellulase activity and sulfate transport gene families

\begin{tabular}{|c|c|c|c|}
\hline Transcript & Seq. description & Fold & $q$ Value \\
\hline \multicolumn{4}{|l|}{ Cellulase activity $^{\mathrm{a}}$} \\
\hline \multicolumn{4}{|l|}{ Upregulated } \\
\hline TCONS_00011897 & Glycosyl transferase & 7.76 & 0.00 \\
\hline TCONS_00011898 & Cellulose synthase catalytic subunit & 7.06 & 0.00 \\
\hline TCONS_00008710 & Glucan- $\beta$-glucosidase & 2.08 & 0.00 \\
\hline TCONS_00000830 & Endo- $\beta$-glycosyl hydrolase & 1.33 & 0.00 \\
\hline TCONS_00016243 & Endoglucanase a precursor & 7.10 & 0.00 \\
\hline TCONS_00005776 & Glycosyl hydrolase family 12 & 1.49 & 0.00 \\
\hline TCONS_00006290 & Endoglucanase a precursor & 1.59 & 0.00 \\
\hline \multicolumn{4}{|l|}{ Downregulated } \\
\hline TCONS_00009010 & Blycosyl hydrolase family 61 & -4.13 & 0.00 \\
\hline TCONS_00014558 & Endoglucanase b & -15.81 & 0.00 \\
\hline TCONS_00014559 & Endoglucanase b & -12.28 & 0.00 \\
\hline TCONS_00012618 & Glycoside hydrolase family 12 & -10.87 & 0.00 \\
\hline TCONS_00008371 & Family 45 cellulase homologue & -10.00 & 0.00 \\
\hline TCONS_00013473 & Extracellular endoglucanase & -8.82 & 0.01 \\
\hline \multicolumn{4}{|c|}{ No significant regulation } \\
\hline TCONS_00005237 & Xyloglucan-specific endoglucanase & 1.10 & 0.21 \\
\hline TCONS_00010110 & Endoglucanase b & -1.37 & 0.30 \\
\hline TCONS_00002734 & Hydrolyzing O-glycosyl & -2.00 & 0.35 \\
\hline TCONS_00014692 & $\beta$-Glucanase & 1 & 0.46 \\
\hline TCONS_00007104 & Phenazine biosynthesis & -1.53 & 0.47 \\
\hline TCONS_00014691 & $\beta$-Glucanase & 1.50 & 0.53 \\
\hline TCONS_00006249 & $\beta$-Glucanase & 3.40 & 0.53 \\
\hline TCONS_00013650 & Glycosyl hydrolase family 7 & 1 & 0.56 \\
\hline TCONS_00009903 & Endoglucanase & 1.70 & 0.64 \\
\hline TCONS_00016450 & Endoglucanase ii & 1.19 & 0.76 \\
\hline \multicolumn{4}{|l|}{ Sulfate transport ${ }^{\mathrm{b}}$} \\
\hline \multicolumn{4}{|l|}{ Upregulated } \\
\hline TCONS_00002171 & Sulfate permease ii & 5.79 & 0.00 \\
\hline TCONS_00004756 & Sulfate permease 2 & 2.76 & 0.00 \\
\hline TCONS_00002173 & Sulfate permease ii & 2.52 & 0.00 \\
\hline \multicolumn{4}{|l|}{ Downregulated } \\
\hline TCONS_00014828 & Cysteine synthase $b$ & -1.67 & 0.00 \\
\hline TCONS_00017544 & Sulfate permease ii & -2.03 & 0.00 \\
\hline TCONS_00014829 & Cysteine synthase $b$ & -2.36 & 0.00 \\
\hline \multicolumn{4}{|l|}{ No regulation } \\
\hline TCONS_00013384 & Rhodanese-containing protein & 1.22 & 0.18 \\
\hline
\end{tabular}

${ }^{a}$ The 23 genes with putative cellulase activity were divided according to their expression in the $\triangle p a c C$ mutant. Upregulated group and downregulated groups are shown.

${ }^{\mathrm{b}}$ Seven sulfate transport genes were similarly divided. For each gene the transcript number, the sequence description, fold change of Colletotrichum gloeosporioides wild type and $\Delta$ pacC mutant, and $q$ value are presented. 
their WT (Bignell et al. 2005; Rollins 2003). In order to estimate pacC regulation of acidifying fungi pathogenicity, we analyzed all known pathogenicity mutants of $B$. cinerea for their best homologs in C. gloeosporioides and found that 7 of 46 mutants are homologs to genes that are regulated by pacC in C. gloeosporioides. Interestingly, all the C. gloeosporioides homologs are downregulated by pacC; therefore, they are acidexpressed (Table 4).

\section{DISCUSSION}

\section{C. gloeosporioides genome.}

C. gloeosporioides (as well as other fungal pathogens) alkalinizes the ambient surroundings during pathogenic colonization of fruit (Alkan et al. 2012a). In this work, the genome of C. gloeosporioides, a successful post-harvest pathogen (Prusky 1996), was sequenced in order to characterize the genes which are controlled by $\mathrm{pH}$ during pathogenicity. Comparison of the C. gloeosporioides genome with other Colletotrichum spp. indicates a similar genome size of $54 \mathrm{Mb}$ and an average GC of $53 \%$, with the exception of $C$. orbiculare. The latter has a significantly expanded genome with many AT blocks potentially arising as the result of transposable element inactivation (Gan et al. 2013). Strikingly, with similar genome size, the $C$.

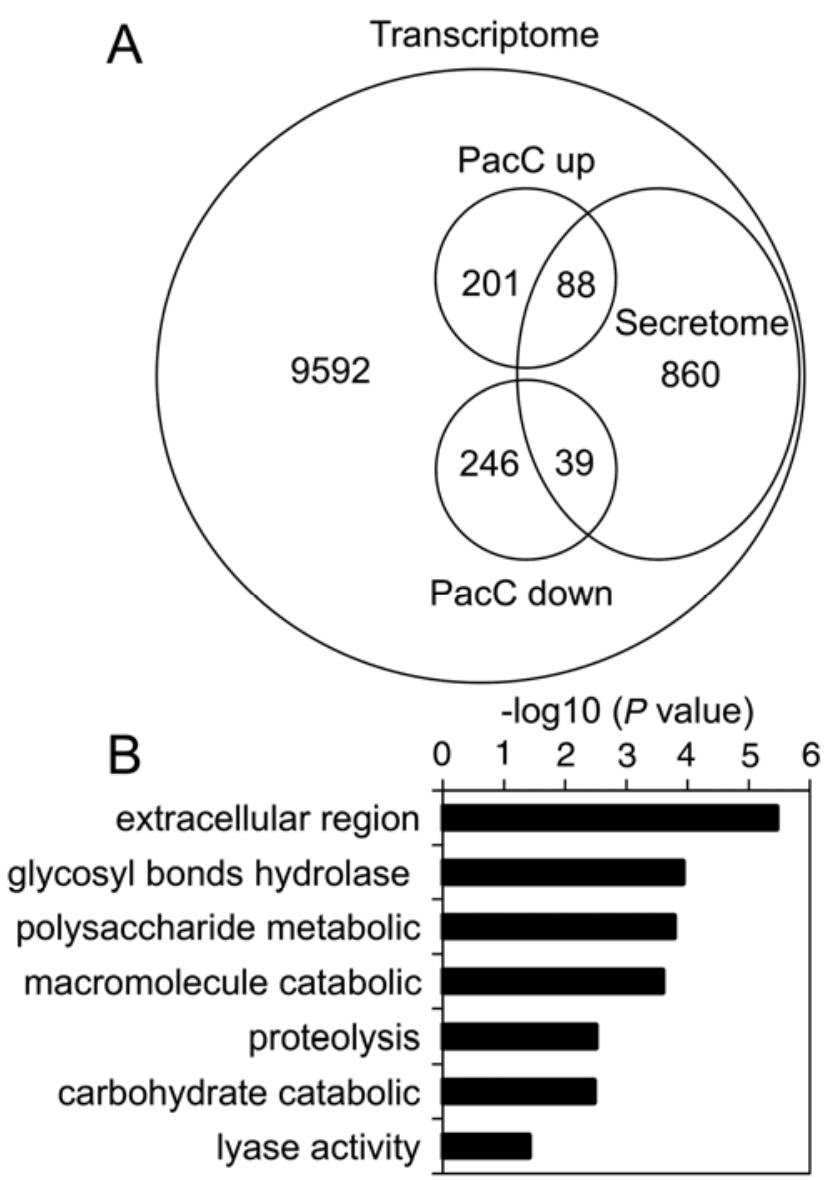

Fig. 5. Characterization of Colletotrichum gloeosporioides pacC-regulated secretome. A, C. gloeosporioides Venn diagram intersection describing the overlap between transcriptome, secretome, and pacC-regulated genes. The $C$. gloeosporioides transcriptome of 9,592 transcripts that have over $90 \%$ homology to the genome-based predicted proteins overlapped with 860 secretome genes and 574 pacC-regulated genes. B, Overrepresentation of Gene Ontology term annotation by Ontologizer program of 88 transcripts, which overlapped between the $C$. gloeosporioides secretome and the pacC-upregulated genes, presented as $-\log 10$ of the $P$ value. gloeosporioides genome contains 14 to $53 \%$ more predicted proteins, suggesting a significantly higher genome complexity.

Moreover, gene cluster analysis showed that $C$. gloeosporioides has larger gene families than found in $C$. higginsianum and C. graminicola. C. gloeosporioides has a wider host range than $C$. higginsianum and $C$. graminicola. Thus, these results may suggest that it needs more genes with various optimum activities to maintain colonization and pathogenicity under the large variety of hosts' environments. Furthermore, the secretome of C. gloeosporioides shows overrepresentation of pathogenicity factors such as CWDE and proteases. When inspecting the numbers of secreted proteins in other Colletotrichum spp., there were lower numbers of secreted proteins in both C. graminicola and $C$. orbiculare, which have a narrower host range compared with $C$. higginsianum and $C$. gloeosporioides (Table 1). A possible reason for the higher number of predicted proteins and gene families could be the reduced host specialization of C. gloeosporioides. C. graminicola attacks mainly corn, C. orbiculare colonizes cucurbits, and Nicotiana benthamiana and C. higginsianum colonize a number of Brassicaceae spp. $C$. gloeosporioides colonizes over 470 different plant and fruit

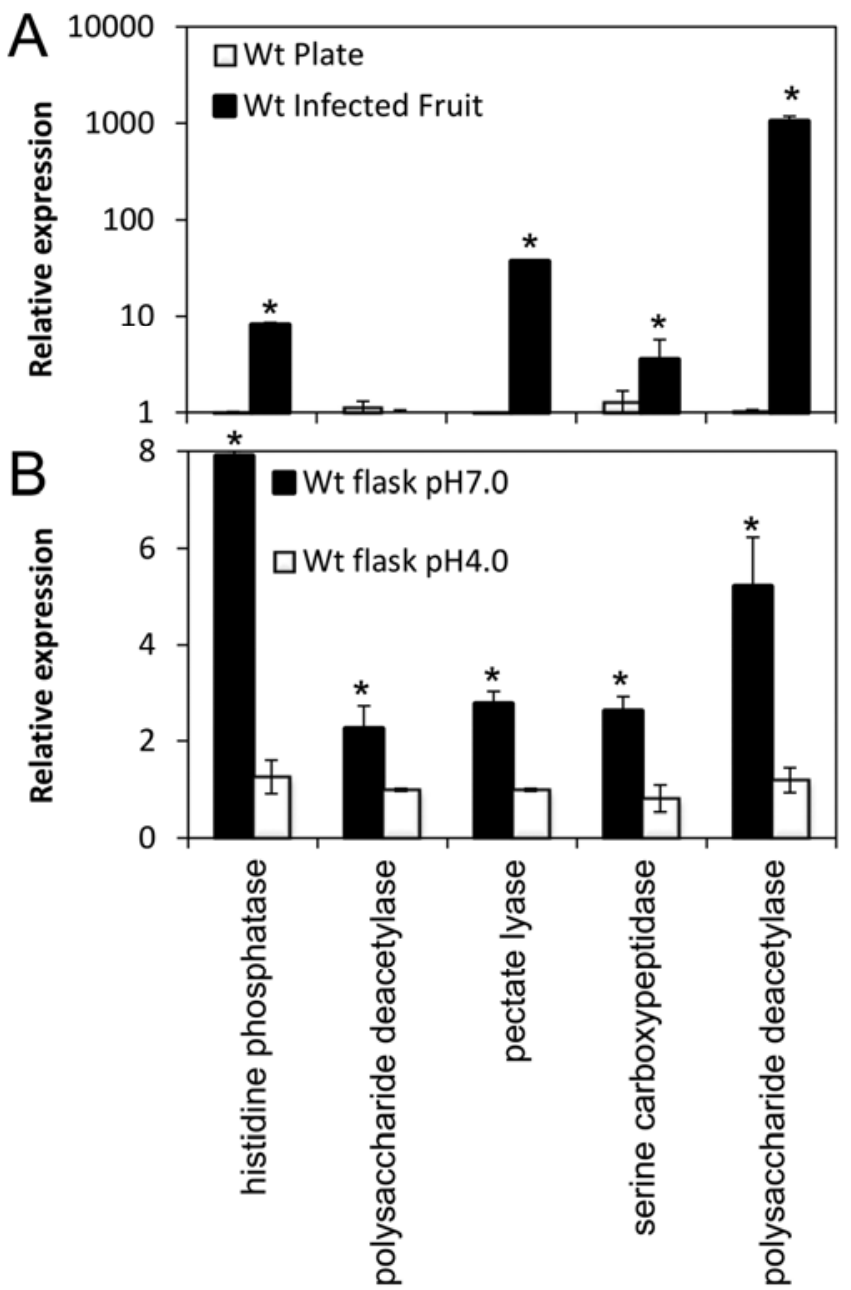

Fig. 6. Relative transcript expression of Colletotrichum gloeosporioides secreted proteins. A, Quantitative reverse-transcriptase polymerase chain reaction (RT-qPCR) average and standard error (SE) relative expression of five selected $C$. gloeosporioides wild-type (WT) secreted and pacC-dependent genes during 2 days of growth on peeled avocado mesocarp fruit compared with expression during in vitro growth conditions in an $\mathrm{M}_{3} \mathrm{~S}$ plate of 1-week-old cultures. B, RT-qPCR average and SE relative expression of five selected $C$. gloeosporioides WT secreted and pacC-dependent genes (TCONS_00014945, TCONS_00000137, TCONS_00014224, TCONS_ 00015963 , and TCONS_00011812) at pH 4.0 and 7.0 after $16 \mathrm{~h}$. 
Table 4. Summary of Colletotrichum gloeosporioides and Botrytis cinerea reduced pathogenicity mutants which are pacC-regulated ${ }^{\mathrm{a}}$

\begin{tabular}{|c|c|c|c|c|}
\hline Candidate gene name & Reference & Pathogenicity $^{b}$ & TCONS & pacC fold change $^{c}$ \\
\hline \multicolumn{5}{|l|}{ C. gloeosporioides } \\
\hline Pectate lyase (PELB) & Yakoby et al. 2001 & + & TCONS_00014224 & $46.8 * * *$ \\
\hline Ammonia exporter (AMET) & Shnaiderman et al. 2013 & + & TCONS_00010049 & $6.9 * * *$ \\
\hline Chitin deacetylase (CDA) & This work & - & TCONS_00011812 & $7.01 * * *$ \\
\hline Aspartic protease (ASP) & This work & + & TCONS_00013084 & $2.04 * * \mathrm{~d}$ \\
\hline Sterol glycosyl transferase (CHIP6) & Kim et al. 2002 & + & TCONS_00013643 & $1.5 * * *$ \\
\hline Ammonium permease (MEPB) & Miyara et al. 2012 & + & TCONS_00015558 & $1.2 * * *$ \\
\hline Glutamate dehydrogenase (GDH) & Miyara et al. 2012 & + & TCONS_00001112 & $-2.5 * *$ \\
\hline \multicolumn{5}{|l|}{ B. cinerea } \\
\hline Pectin methylesterase (PME) & Valette-Collet et al. 2003 & + & TCONS_00004801 ${ }^{\mathrm{e}}$ & $-87.23 * * *$ \\
\hline Polygalacturonase1 (PG1) & ten Have et al. 1998 & + & TCONS_00010609 & $-24.5 * * *$ \\
\hline Cytochrome p450 monooxygenase (BOT1) & Siewers et al. 2005 & + & TCONS_00016890 & $-3.5 * * *$ \\
\hline Endopolygalacturonase2 (PG2) & Kars et al. 2005 & + & TCONS_00005487 & $-3.24 * *$ \\
\hline Endo- $\beta-1,4$ xylanase & Brito et al. 2006 & + & TCONS_00011297 & $-1.61 *$ \\
\hline Tetraspanin 1 (PLS1) & Gourgues et al. 2004 & ++ & TCONS_00017362 & $-1.4 * * *$ \\
\hline Chitin synthase 1 (CHS1) & Soulie et al. 2003 & + & TCONS_00006342 & $-1.4 *$ \\
\hline
\end{tabular}

${ }^{\text {a }}$ Summary of $C$. gloeosporioides reduced pathogenicity gene knockouts which are pacC regulated and $B$. cinerea pathogenicity reduced mutants whose best homologs are pacC regulated. Presented are the gene names, reference, pathogenicity effect, $C$. gloeosporioides TCONS number for each mutant, and pacC fold change in C. gloeosporioides.

${ }^{\mathrm{b}}$ Pathogenicity reductions: - represents nonsignificant pathogenicity reduction, + represents significant pathogenicity reduction, and ++ represents a complete loss of pathogenicity.

${ }^{\mathrm{c}}$ Statistical significance ( $q$ value of RNA-seq after false discovery rate correction) is represented by asterisks, where $*, * *$, and $* * *$ indicate lower than 0.05 , 0.01 , and 0.001 , respectively.

${ }^{\mathrm{d}}$ Based on quantitative reverse-transcriptase polymerase chain reaction analysis.

${ }^{\mathrm{e}}$ Lowest e-value blast scores were chosen (5e-56 or below).

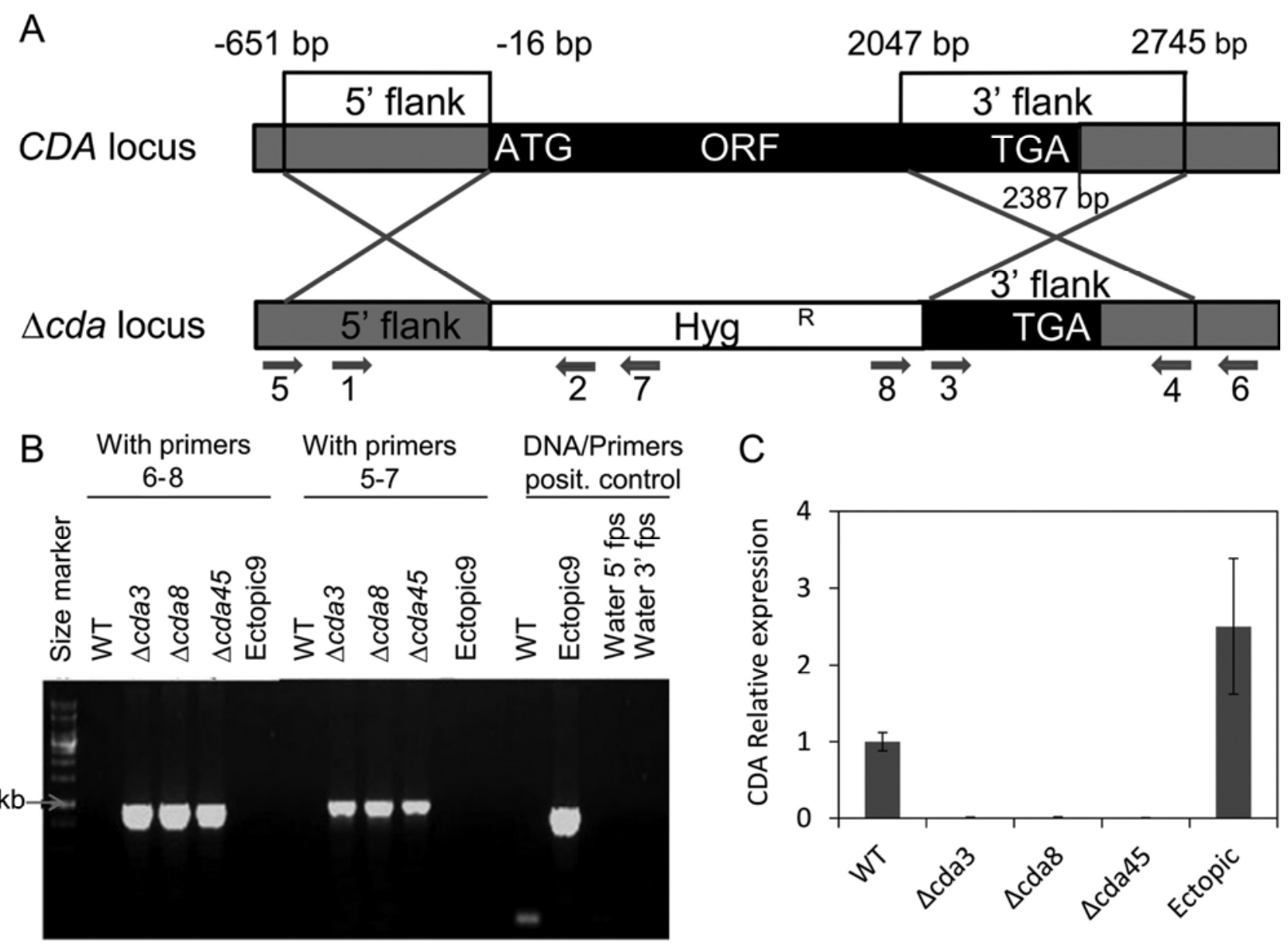

Fig. 7. Construction and analysis of chitin deacetylase $(C D A)$ gene deletion transformants. A, Schematic representation of a double crossing-over homologous recombination event resulting in replacement of part of the $C D A$ open reading frame sequence with the hygromycin-resistance gene cassette HygR flanked by $5^{\prime}$ and $3^{\prime} C D A$ genomic fragments. B, Polymerase chain reaction (PCR) analysis of the wild type (WT) and three independent $C D A$-disruption strains. Primer5 (cda5Fctrl) positioned upstream of the CDA:HYG region and reverse primer 7 located on the hygromycin resistance gene were used to identify positive gene replacement at the $5^{\prime}$ end. Primer 8 from the hygromycin cassette and primer 6 downstream of the CDA:HYG region (cda5Rctrl) were used to identify gene replacement at the $3^{\prime}$ end. Primer 1 and 7 set was used as a positive control for the ectopic strains, to confirm random integration of the CDA:HYG cassette. C, Expression of $C D A$ gene in the $\Delta c d a$ strains compared with the ectopic-integration control and WT strains, as detected by real-time PCR. Cultures were initially grown in primary medium for 3 days and subsequently transferred to secondary media at pH 4.0 and supplemented with 50 mM glutamate for $16 \mathrm{~h}$, prior to RNA extraction. 
species and may employ a larger genome to maintain a more diverse array of genes to support colonization under varied conditions (Staats et al. 2005). Genome complexity is inversely related to specialization in other organisms, where evolution toward specialization was found to be associated with extensive genome reduction (Nilsson et al. 2005). Thus, in a similar manner, the root pathogen Meloidogyne hapla has fewer genes than the related free-living Caenorhabditis elegans (Opperman et al. 2008).

In addition to differences in genome complexity, the chromosome conservation between Colletotrichum gloeosporioides and $C$. graminicola shows only $30 \%$ synteny, with multiple gene rearrangements. The blocks of synteny were limited mainly to translated areas in the genome. This level of synteny is similar to that found between $C$. higginsianum and C. graminicola (O'Connell et al. 2012). Synteny analysis of transcripts between $C$. orbiculare and $C$. gloeosporioides showed 53 to $60 \%$ conservation of expressed genes (Gan et al. 2013). This observation is consistent with conservation among Colletotrichum spp. being higher at the gene level than at the chromosome level. Synteny comparisons between different strains of C. gloeosporioides (i.e., within the same species) resulted in $89 \%$ similarity, expectedly higher that the synteny between species of the Colletotrichum genus. However, the genome di- vergence is still significant and is consistent with the relatively high dissimilarity found using select gene sequence comparisons of $C$. gloeosporioides isolates, as observed by Weir and associates (2012).

PacC shows dual regulation of genes under $\mathrm{pH}$ change.

Yeast and fungi have utilized $R I M$ or pacC, respectively, as mechanisms to monitor and respond to external $\mathrm{pH}$ in order to survive under varied $\mathrm{pH}$ conditions (Penalva et al. 2008; Selvig and Alspaugh 2011). Because pacC is a transcription factor that regulates gene expression under alkaline conditions, we characterized the transcription of upregulated genes as alkaline-expressed genes and downregulated genes as acidexpressed genes. In the present work, we characterized the global control of pacC with RNA-seq by taking advantage of the fact that $\triangle p a c C$ behaves as an acid-mimicking mutant even under alkaline conditions (Tilburn et al. 1995). We confirmed this rationale by measuring pacC-regulated genes with RTqPCR in actual pH shifts. Furthermore, the expression of homologs of pacC-regulated genes from the acidifying type of pathogen, S. sclerotiorum, showed that their $\mathrm{pH}$-dependent expression pattern was similar to a pathogen which alkalizes environment, $C$. gloeosporioides. This indicates similar control for homologous genes despite the different optimum of $\mathrm{pH}$

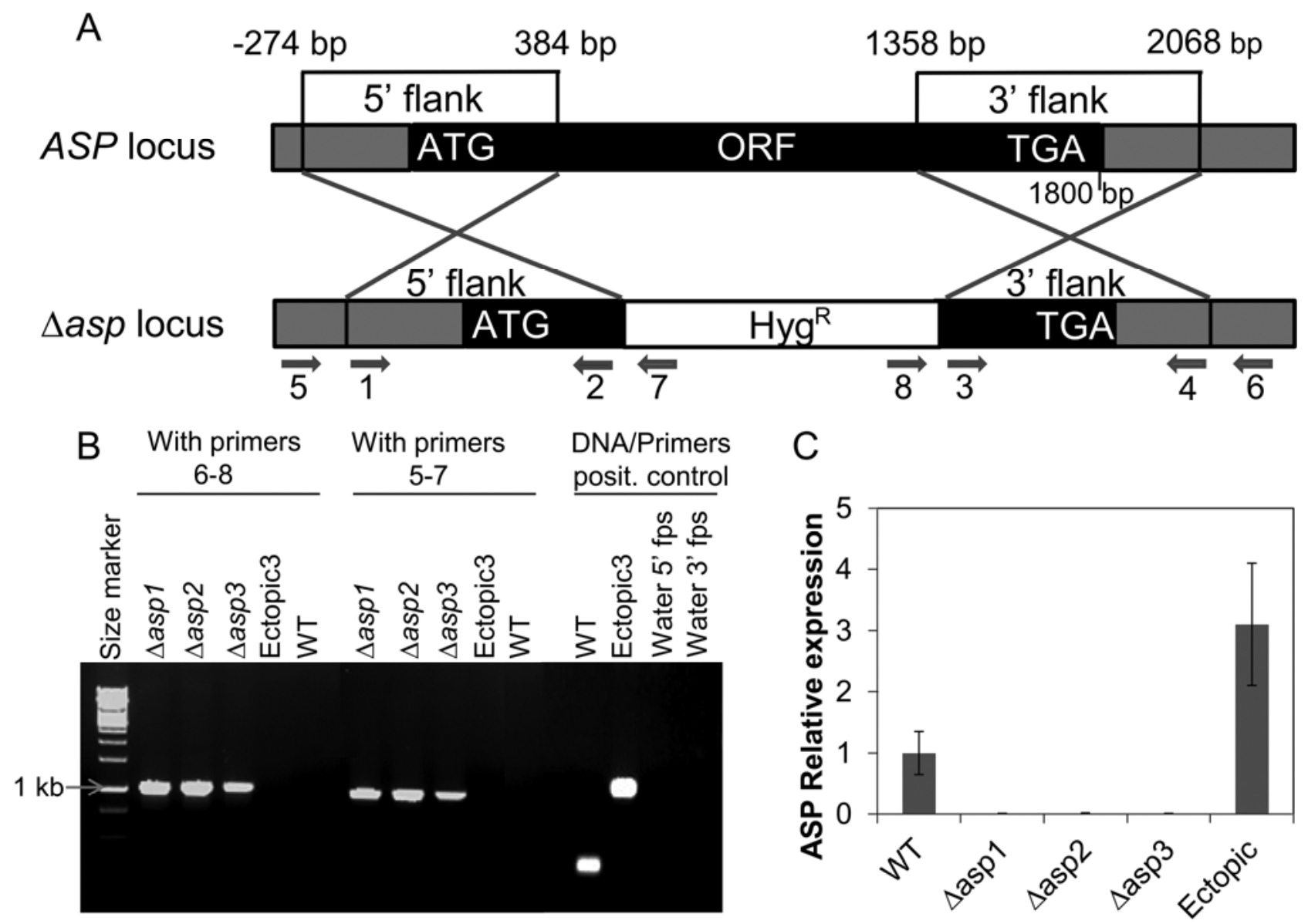

Fig. 8. Diagram construction and analysis of aspartic protease (ASP) gene deletion transformants. A, Schematic representation of a double crossing-over homologous recombination event resulting in replacement of part ASP open reading frame sequence with the hygromycin-resistance gene cassette HygR flanked by $5^{\prime}$ and $3^{\prime} A S P$ genomic fragments. B, Polymerase chain reaction (PCR) analysis of the wild type (WT) and three potential independent $A S P$-disruption strains. Primer5 (asp5Fctrl) positioned upstream of the $A S P: H Y G$ region and reverse primer 7 located on the hygromycin resistance gene were used to identify positive gene replacement at the $5^{\prime}$ end. Primer 8 from the hygromycin cassette and primer 6 downstream of the $A S P: H Y G$ region (asp5Rctrl) were used to identify gene replacement at the $3^{\prime}$ end. Primer 1 and 7 set was used as a positive control for the ectopic strains, to confirm random integration of the ASP:HYG cassette. C, Expression of ASP gene in the $\triangle a s p$ strains compared with the ectopic-integration control and WT strains, as detected by realtime PCR. Cultures were initially grown in primary medium for 3 days and subsequently transferred to secondary media at pH 4.0 and supplemented with 50 $\mathrm{mM}$ glutamate for $16 \mathrm{~h}$, prior to RNA extraction. 
growth requirements for each fungus. Thus, it is likely that fungi with different $\mathrm{pH}$ preferences contain an arsenal of both alkaline- and acid-regulated genes in order to exploit changing $\mathrm{pH}$ conditions. Hence, at each $\mathrm{pH}$, the fungus is likely to express an optimal gene combination.

Assessment of the functions of genes regulated by pacC revealed those that function in various cellular activities. These include transporters, antioxidants, and CWDE. Transporters, including those involved in sulfate, potassium, carboxylic acid, and ammonium transport, are likely candidates controlled by $\mathrm{pH}$ due to the direct $\mathrm{pH}$ effect on charge of inorganic or organic acid ions. The upregulation of transporters may compensate for changes in ion difference between intracellular and the extracellular regions in order to restore fungal homeostasis under changing $\mathrm{pH}$, as observed in yeast (Bensen et al. 2004). Apparently, the $\mathrm{pH}$ shifts also affect cellular redox states, as exemplified by changes in antioxidants that include catalase activity and hydrogen peroxide catabolic process.

Major components of pacC regulation in C. gloeosporioides are CWDE pathogenicity factors. Groups of genes that are shown to be affected here by pacC include PelB, cellulase, $\alpha$ mannosidase, and 1,4- $\beta$-xylanase activity. These findings extend the repertoire of $\mathrm{pH}$-modulated CWDE from the previously identified PelB in C. gloeosporioides and endoglucanases in Alternaria alternata (Eshel et al. 2002; Prusky et al. 2001, 2004; Yakoby et al. 2000). The results are consistent with the observation that $\Delta$ pacC mutants of $C$. gloeosporioides, $C$. acutatum, $F$. oxysporum, and $S$. sclerotiorum were found to be less virulent than the WT (Caracuel et al. 2003a,b; Miyara et al. 2008; Rollins 2003; You et al. 2007).

Interestingly, gene families with members of similar functionality were both up- and downregulated by pacC. These included CWDE such as rhamnogalacturonan lyase activity, pectin catabolic, polygalacturonase activity, carbon-sulfurlyase, $\beta$-1,4-glucanase, xyloglucan catabolic activity, aspartic-type peptidase, $\beta$-mannosidase activity, and cellulase activity. In an analogous manner, in $S$. sclerotiorum, it was demonstrated that the expression of polygalacturonase $\mathrm{A}$ and $\mathrm{B}$ was $\mathrm{pH}$ dependent and correlated with the optimal $\mathrm{pKa}$ of each protein (Favaron et al. 2004). The differential $\mathrm{pH}$ regulation of genes with similar activities suggests that genes are being selectively activated on the basis of their optimal enzymatic $\mathrm{pH}$ activity, allowing the

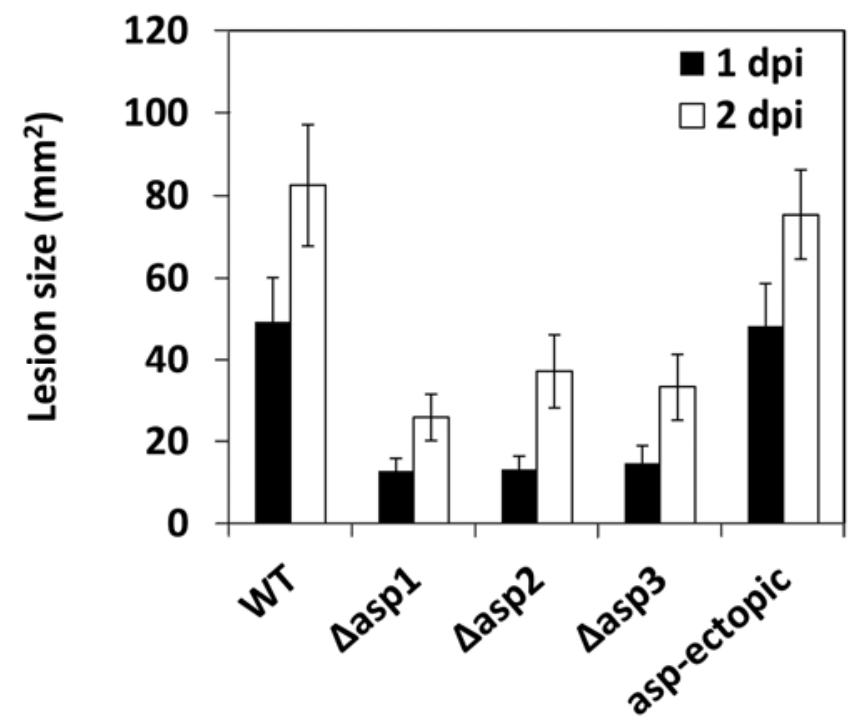

Fig. 9. Pathogenicity assay for $\Delta a s p$ mutants. Changes of decay size inoculated by the wild type and three independent $\Delta a s p$ mutants on avocado fruit 1 and 2 days postinoculation (dpi). fungus to cope with variable $\mathrm{pH}$ conditions and make optimal use of the inventory of available enzymes. Differential regulation of family members with similar function extends to other functions, including transporters for organic alcohol, hydrogen ions, and sulfate. Thus, the function of pacC is not to switch on or off a new life stratagem but to assist in the fine-tuning of the expression of transporters and antioxidants to maintain homeostasis and expression of pathogenicity factors for orchestration of the genomic arsenal under changing $\mathrm{pH}$. Conceptualization of fungal pacC $\mathrm{pH}$-dependent regulation of gene expression is shown schematically in Figure 10.

It is of interest that, when known pathogenicity genes of the acidifying fungus $B$. cinerea are examined, the best homologs of those genes in $C$. gloeosporioides are actually under pacC control and were acid expressed. Furthermore, several polygalacturonases were acid expressed and pacC-dependent in B. $\mathrm{Ci}$ nerea and in $S$. sclerotiorum and affected fungal pathogenicity (Favaron et al. 2004; Kars et al. 2005; Rollins and Dickman 2001; Wubben et al. 2000). Those findings are consistent with a scenario in which pacC controls the fine-tuning of enzymes so that the optimum repertoire will be expressed at any given $\mathrm{pH}$. Those acid-expressed-genes are crucial for $B$. cinerea pathogenicity because it thrives at low $\mathrm{pH}$. Therefore, in a fungus that acidifies its surroundings, pacC will probably activate alkaline-expressed genes and repress acid-expressed genes transiently during initial colonization until the secretion of acids lowers the environmental $\mathrm{pH}$. Reciprocally, in fungi that alkalinize the environment, pacC will be activated only after the fungi raise the surrounding $\mathrm{pH}$. Because fungi are likely to encounter a broad spectrum of initial environmental $\mathrm{pH}$, broad conservation of $\mathrm{pH}$ response has justification independent of the preferred $\mathrm{pH}$ for pathogenicity.

\section{PacC regulation of alkalizing and acidifying genes.}

C. gloeosporioides secretes ammonia in order to alkalinize its surroundings (Prusky et al. 2001). Analysis of the $\Delta p a c C$ transcriptome identified a number of genes involved in nitrogen and ammonia metabolism. Genes encoding the production of ammonia such as GDH and urease were downregulated and are acid expressed, whereas genes coding for ammonia transport such as AMET, urea transporter, and MEPB were upregulated (Supplementary Table S6). These observations are in agreement with the fact that GDH is acid expressed and MEP is alkaline expressed (Miyara et al. 2010). Hence, pacC controls the ammonia production and secretion. When faced with an acidified environment, Colletotrichum spp. induced ammonia secretion in order to alkaline the environment to achieve

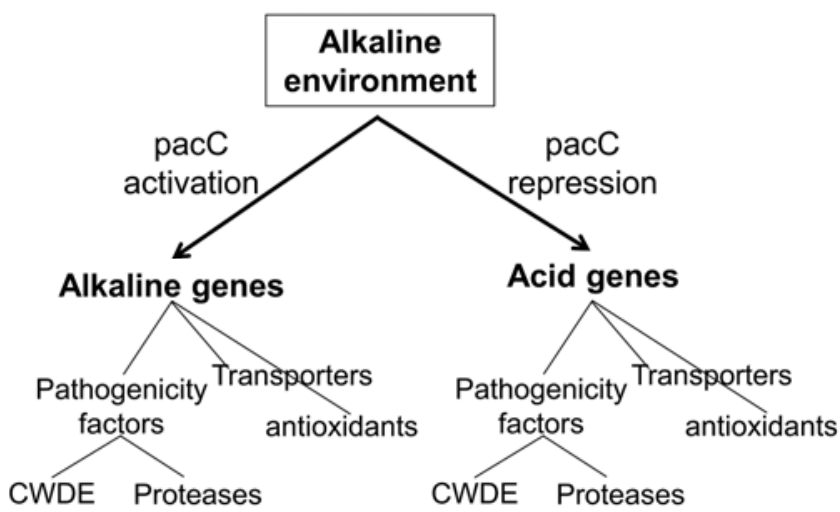

Fig. 10. Scheme illustrating pacC regulation in Colletotrichum gloeosporioides and in other fungi. Alkaline environments activate pacC that positively or negatively regulates alkaline- or acid-expressed genes, including pathogenicity factors (cell-wall-degrading enzymes [CWDE] and proteases), transporters, and antioxidants. 
their optimum growth and pathogenicity (Alkan et al. 2008; Kramer-Haimovich et al. 2006).

\section{Secretome and pathogenicity factors in fungi that alkalinize or acidify.}

The predicted secretome showed enrichment for pacCupregulated genes containing 3.3-fold more genes than expected. Assessment of gene functions showed a significant overrepresentation of catabolic activity such as CWDE and proteolysis which we termed "pathogenicity factors". Expression profiling of selected genes from the pacC-upregulated and -secreted genes confirmed transcript activation at alkaline $\mathrm{pH}$ and during necrotrophic infection, which indicates that they may contribute to fungal pathogenicity. Indeed, functional analysis of six C. gloeosporioides $\mathrm{KO}$ mutants that are regulated by pacC showed reduced pathogenicity (Table 4). Thus, a secreted CWDE, PelB, was shown to be pacC regulated (46fold) and the pelB null mutants showed reduced pathogenicity (30\%) (Table 4) (Miyara et al. 2008; Yakoby et al. 2001). In addition, the pacC-controlled secreted $A S P$ was shown to be a pathogenicity factor, as the ASP KO mutant showed $50 \%$ reduction of pathogenicity on avocado fruit (Fig. 9). Another pacC-controlled and secreted gene is the polysaccharide $C D A$ that was found to be part of a gene family. However, its deletion did not show a reduction in pathogenicity. In that case, two additional putative $C D A$ genes were shown to be strongly upregulated in the mutant background. Thus, the inability to detect a reduction in pathogenicity may be due to functional redundancy.

In addition to CWDE and proteases, ammonia was also shown to regulate Colletotrichum pathogenicity (Alkan et al. 2008, 2009). Here, we show that pacC controls the AMET and $M E P B$ transcripts, and both of their C. gloeosporioides null mutants showed reduced pathogenicity (Table 4) (Miyara et al. 2012; Shnaiderman et al. 2013). Interestingly, $G D H 2$ is a main factor in the production of ammonia and is active at acidic $\mathrm{pH}$. Thus, its activity contributes to ambient alkalization. GDH2 is negatively regulated by pacC and its null mutant displays reduced pathogenicity (Table 4) (Miyara et al. 2012). This indicates that pacC control of $C$. gloeosporioides pathogenicity is not limited to regulation of CWDE, proteases, and ammonia transporters in alkaline surroundings. It also plays a direct role in the negative regulation of ammonia production under alkaline conditions, thus promoting ammonia accumulation under acidic conditions in order to alkalinize the surroundings.

Interestingly, analysis of the results here reveals that deletion mutants of homologs of seven acid-expressed genes are crucial for $B$. cinerea pathogenicity. This indicates pacC control of alkaline- and acid-expressed genes that have a major role in fungal pathogenicity in both fungi that acidify or alkalinize their surroundings. In fungi that thrive in alkaline environments such as Colletotrichum spp., the alkaline-induced genes display pathogenicity roles whereas, with fungi that thrive in acidic environment such as Botrytis spp., the acid-expressed genes display pathogenicity roles.

\section{Summary.}

The postharvest multihost pathogen $C$. gloeosporioides genome sequence is similar in size to the other Colletotrichum spp. but displays more complexity because it possesses more genes. Transcriptome analysis of $\mathrm{pH}$ control by pacC revealed an arsenal of pathogenicity factors, transporters, and antioxidants to control virulence and homeostasis under changing ambient $\mathrm{pH}$ conditions (Fig. 10). Comparison of diverse fungal genomes showed a similar strategy of control by pacC, indicating a conserved role in regulating fungal genes. The observations were supported by functional analyses of both fungi that alkalize or acidify their surroundings. The results also indicated that several pacC-regulated genes have a major impact on pathogenicity.

\section{MATERIALS AND METHODS}

Fungal isolate, media, and growth conditions.

Single-spore cultures of the WT Cg-14 isolate of C. gloeosporioides were obtained from a decayed avocado fruit (Persea americana 'Fuerte') in Israel and were routinely cultured on $\mathrm{M}_{3} \mathrm{~S}$ agar. C. gloeosporioides $\triangle P A C 1$ loss-of-function mutants that encode the pacC transcription factor (Miyara et al. 2008) were routinely cultured on $\mathrm{M}_{3} \mathrm{~S}$ agar (Tu 1985). $\mathrm{M}_{3} \mathrm{~S}$ medium without agar (primary medium) was also used for the initial growth of the fungus, prior to exposing it to secondary media (SM). The cultures were incubated at 22 to $24^{\circ} \mathrm{C}$ in a shaking incubator at $150 \mathrm{rpm}$ for 3 days and were harvested by filtration through a sterile Buchner funnel fitted with Whitman filter paper. The hyphal mat was washed twice with $40 \mathrm{ml}$ of sterile distilled water. The washed mycelia were resuspended in 40 $\mathrm{ml}$ of fresh SM containing the following reagents (per liter): $4 \mathrm{~g}$ of $\mathrm{K}_{2} \mathrm{HPO}_{4}, 2 \mathrm{~g}$ of $\mathrm{MgSO}_{4} \cdot 7 \mathrm{H}_{2} \mathrm{O}, 0.3 \mathrm{~g}$ of $\mathrm{CaCl}_{2} \cdot 2 \mathrm{H}_{2} \mathrm{O}, 10 \mathrm{mg}$ of $\mathrm{FeCl}_{3}, 50 \mathrm{mM} \mathrm{KNO}_{3}$ and $50 \mathrm{mM}$ glucose. The SM was buffered with $50 \mathrm{mM}$ phthalate-hydroxide buffer (Sigma, Rehovot, Israel) to obtain $\mathrm{pH} 4.0$ or 7.0. The efficacy of the $\mathrm{pH}$ buffering was confirmed at the end of the experiment. For transcriptome analysis (RNA-seq), a pool of mycelium was harvest after growth of the $C$. gloeosporioides WT and pacC mutant at $\mathrm{pH} 7.0$ for $1,3,6,12$, and $19 \mathrm{~h}$. Each time point was composed of five biological RNA extractions, and the pooled timepoint and repeats were served for transcriptome analysis.

S. sclerotium isolate 1980 was routinely cultured on potato dextrose agar. Five $10-\mathrm{mm}^{2}$ plugs of 5-day-old S. sclerotium culture was grown initially for $48 \mathrm{~h}$ in $40 \mathrm{ml}$ of potato dextrose broth (PDB) liquid media and transferred to PDB buffered with $50 \mathrm{mM}$ phthalate-hydroxide (Sigma) to obtain $\mathrm{pH} 4.0$ or 7.0 for $8 \mathrm{~h}$.

\section{Fruit inoculation.}

Freshly harvested, ripe Fuerte avocado fruit were used for inoculations. Spores of C. gloeosporioides strains were inoculated on the avocado pericarp by placing $10 \mu \mathrm{l}$ of a conidial suspension $\left(10^{6}\right.$ conidia $\left.\mathrm{ml}^{-1}\right)$ into 1-mm-deep, 1-mm-diameter inoculation spots. When fruit were inoculated on the mesocarp, a 1- to 2-mm strip of peel tissue was removed from the surface of fruit and $7 \mu \mathrm{l}$ of a conidial suspension was used. Five inoculation spots, longitudinally spaced on each side of each of 10 different fruit, were inoculated per treatment.

\section{Genome sequencing, assembly, and annotation.}

C. gloeosporioides was grown for 3 days on liquid $\mathrm{M}_{3} \mathrm{~S}$ media and DNA was extracted from $100 \mathrm{mg}$ of mycelia using the Puregene DNA purification system (Gentra, Minneapolis, MN, U.S.A.). The purified genomic DNA was sequenced to a depth of approximately 10x using 454 GS FLX Titanium technology. The sequence reads was assembled using the GS De Novo Assembler software (454 Corp) yielding 4,907 contigs larger than 500 bp (SUB133583). Sequencing and assembly were performed by the Roy J. Carver Biotechnology Center, University of Illinois at Urbana-Champaign. Gene models were annotated using GeneMark-ES (Ter-Hovhannisyan et al. 2008).

\section{Protein sequence clustering.}

The protein sequences encoded by the gene models predicted for $C$. gloeosporioides were clustered together with the predicted proteins from C. graminicola, C. higginsianum, Neurospora crassa, Aspergillus nidulans, S. sclerotiorum, and $B$. 
cinerea. The protein sequences for each species were downloaded from the respective genome portals on the websites of the Broad Institute and the Joint Genome Institute. The clustering was performed using the software MCL (van Dongen 2000) using an inflation parameter of 2.0.

\section{Analysis of conserved synteny.}

Conserved syntenic blocks between the $C$. gloeosporioides and $C$. graminicola genomes were identified using SyMAP 4.0 (Soderlund et al. 2006) using the default parameters. Pseudochromosome sequences for $C$. graminicola were reconstructed using the information available on the Broad Institute website. All C. gloeosporioides contigs larger than 10,000 bp were used for the synteny analysis. Due to the large number of contigs in the $C$. gloeosporioides $\mathrm{Cg}-14$ and NARA cg-5 genome assembly, a detailed analysis of conserved synteny was prevented. Instead, we aligned the genomes of $C$. gloeosporioides NARA gc-5 and Cg-14 using Mauve (Darling et al. 2010). The progressive Mauve algorithm first constructs anchor alignments and then joins the anchors into locally collinear blocks.

\section{RNA extraction and real-time PCR analysis.}

RNA was extracted from 80 to $100 \mathrm{mg}$ (dry weight) of $C$. gloeosporioides mycelium or inoculated fruit mesocarp. Samples were ground into fine powder and were extracted using Tri-reagent at $100 \mathrm{mg} / \mathrm{ml} \mathrm{(38 \%} \mathrm{water} \mathrm{saturated} \mathrm{phenol,} 0.8 \mathrm{M}$ guanidine thiocyanate, $0.4 \mathrm{M}$ ammonium thiocyanate, $0.1 \mathrm{M}$ sodium acetate [pH 5], and 5\% glycerol). Aqueous phase was subsequently extracted twice with chloroform. Following isopropanol precipitation and two $70 \%$ ethanol washes, the RNA pellet was resuspended in sterile distilled water. The RNA was treated with 1 unit of DNase, amplification grade (Sigma), and stored at $-80^{\circ} \mathrm{C}$.

The RT reaction was performed on $1 \mu \mathrm{g}$ of total RNA with the high-capacity cDNA Reverse-Transcription Kit (AB, Applied Biosystems, Foster, CA, U.S.A.). Samples of cDNA were diluted 1:10 to the final template concentration for real-time PCR. Real-time RT-qPCR was performed using StepOnePlus System (AB, Applied Biosystems, Singapore). PCR amplification was performed with $3.4 \mu \mathrm{l}$ of diluted cDNA template in $10 \mu \mathrm{l}$ of reaction mixture containing $5 \mu \mathrm{l}$ of Syber-Green amplification kit (AB Gene) and $300 \mathrm{nM}$ primers. PCR was carried out by using the following cycling program: $10 \mathrm{~min}$ at $94^{\circ} \mathrm{C}$, followed by 40 cycles of $94^{\circ} \mathrm{C}$ for $10 \mathrm{~s}, 60^{\circ} \mathrm{C}$ for $15 \mathrm{~s}$, and $72^{\circ} \mathrm{C}$ for $20 \mathrm{~s}$. The samples were subjected to melting curve analysis, with efficiencies close to $100 \%$ for all primers pairs, and all products showed the expected size of 70 to $100 \mathrm{bp}$. All the samples were normalized to actin-related expression levels in C. gloeosporioides and actin in S. sclerotium (Miyara et al. 2012) and the values were expressed as the change in the increase or decrease of the relative levels of a calibrator sample. The actin-related gene was chosen as a suitable reference gene after its expression showed no change during transcriptome evaluation. All primers are listed in Supplementary Table S7. Each treatment consisted of three biological repeats and three technical replicates.

\section{High-throughput sequencing RNA-seq of C. gloeosporioides $\Delta$ pacC.}

RNA high-throughput sequencing (HTS) of C. gloeosporioides WT and $\Delta$ pacC grown at $\mathrm{pH} 7.0$ was conducted (as described above). RNA of five biological repeats from five time points $(1,3,6,12$ and $19 \mathrm{~h})$ was extracted (as described above) and mixed to obtain a pool of $10 \mu \mathrm{g}$ of total RNA. cDNA libraries were prepared for sequencing according to the manufacturer's instructions (True Seq; Illumina Inc., San Diego,CA, U.S.A.). Single-end reads of 101 bases were obtained using
Illumina HiSeq 2000. CASAVA version 1.8.1 was used to generate the raw fastq reads. Genome assemblies of $C$. gloeosporioides isolate $\mathrm{Cg}-14$ using 454 pyro-sequencing technologies platforms of HTS were used as a reference. The hybrid assembly RNA HTS National Center for Biotechnology Information accession number is GSE41844. The C. gloeosporioides WT and $\triangle p a c C$ pooled RNA-seq resulted in 6,974,185 and 4,242,258 reads, of which approximately $70 \%$ of the reads could be mapped perfectly to the $C$. gloeosporioides genome, resulting in 2,938,268 and 4,998,444 aligned reads, respectively.

The reads were aligned to the contigs of $C$. gloeosporioides genome using TopHat v1.3.0 (Trapnell et al. 2009). The resulting alignment data from TopHat were united and fed to Cufflinks v1.1.0 to assemble aligned RNA-Seq reads into transcripts. Transcript abundances were estimated for each sample in Partek Genomics Suite V6.6 beta. Reads per kilobase per million, as well as $P$ value for differential expression using the log-likelihood ratio statistic, were calculated in Partek. The $P$ values were corrected in Partek for multiple comparisons using the step-up method for false discovery rate (Benjamini and Hochberg 1995). Step-up-adjusted $P$ values smaller than 0.05 were referred as significant.

\section{Gene annotation and ontologies.}

Functional annotation was performed using Blast2GO software (Conesa and Gotz 2008) on the Cufflink-identified transcripts searches of the nonredundant database to estimate potential function of the Cufflink-predicted transcript and includes enzyme code, InterPro annotation, and KEGG number maps. Predicted proteins were classified as proteases by querying the MEROPS database (Rawlings et al. 2012) using a BLASTp with cut-off at E-value of 1E-10.

The up- and downregulated genes that were significantly changed by twofold or more were classified to groups according to their Gene Ontology annotation using the Ontologizer software (Bauer et al. 2010). Due to the presence of some genes in multiple GO annotation terms, a representative term from each cluster of was manually selected.

\section{C. gloeosporioides CDA and ASP gene disruption and mutant characterization.}

Gene disruption of CDA (TCONS_00011812) was done by integrating the hygromycin marker gene and $C D A$ flanking sequences. This was carried out by amplifying a 668-bp 5' flanking sequence of the CDA gene on $C$. gloeosporioides genomic DNA. The CDA $3^{\prime}$ region was isolated on genomic DNA by using the modified primer pair located in the CDA $3^{\prime}$ flanking sequence. The two PCR products were assembled together with the Hyg entry clone plasmid, using the Multisite Gateway three-fragment vector construction system. Full details of this methodology are described by Shafran and associates (2008). The NotI fragment was used to create the CDA knockout. Fungal transformation was done by electroporation of germinated conidia, using an established protocol (Yakoby et al. 2001). A PCR screen of the putative transformants was employed with two sets of primers and primer set HYG. A similar procedure was used to create a Gene-blast construct for ASP (13155_t), with corresponding primers: primer asp1-asp2 and primer asp3-asp4 for the PCR ASP 5' and 3' flanking sequences (658 and $710 \mathrm{bp}$, respectively), and primer asp5-HygR(7), and primer asp6-HygF(8) for PCR screening of the putative transformants from the $5^{\prime}$ and $3^{\prime}$ ends, respectively.

\section{Statistical analysis.}

Statistical overrepresentation of GO annotation was done using Ontologizer software (Bauer et al. 2010), with the settings 
of Benjamini-Hochberg, Topology-weighted analysis, and $P$ value lower than 0.05 . The statistical significance between overlapping groups was calculated using the representation fold factor that represents the number of overlapping genes divided by the expected number of overlapping genes drawn from two independent groups. The possibility that these factors are a random event was calculated by hyper-geometric probability. The statistical differences between two average results from RT-qPCR were checked for significance by $t$ test.

\section{ACKNOWLEDGMENTS}

We acknowledge the financial support of BARD through project I-IS4469-11R to D. Prusky, the China Scholarship Council (CSC)-Israel ARO Postdoctorate Scholarship cooperation for X. Meng, and Ministerio de Ciencia e Innovación of Spain (grant number AGL2011-29446AGR) Ramón and Cajal Program for M. Thon and S. Sukno, ISF, Israel Science Foundation 1266/12.

\section{LITERATURE CITED}

AbuQamar, S., Chen, X., Dhawan, R., Bluhm, B., Salmeron, J., Lam, S., Dietrich, R. A., and Mengiste, T. 2006. Expression profiling and mutant analysis reveals complex regulatory networks involved in Arabidopsis response to Botrytis infection. Plant J. 48:28-44.

Alkan, N., Fluhr, R., Sherman, A., and Prusky, D. 2008. Role of ammonia secretion and $\mathrm{pH}$ modulation on pathogenicity of Colletotrichum coccodes on tomato fruit. Mol. Plant-Microbe Interact. 21:1058-1066.

Alkan, N., Davydov, O., Sagi, M., Fluhr, R., and Prusky, D. 2009. Ammonium secretion by Colletotrichum coccodes activates host NADPH oxidase activity enhancing host cell death and fungal virulence in tomato fruits. Mol. Plant-Microbe Interact. 22:1484-1491.

Alkan, N., Espeso, E. A., and Prusky, D. 2012a. Virulence regulation of phytopathogenic fungi by $\mathrm{pH}$. Antioxid. Redox. Signal. Published online.

Alkan, N., Fluhr, R., and Prusky, D. 2012b. Ammonium secretion during Colletotrichum coccodes infection modulates salicylic and jasmonic acid pathways of ripe and unripe tomato fruit. Mol. Plant-Microbe Interact. 25:85-96.

Andersen, M. R., Lehmann, L., and Nielsen, J. 2009. Systemic analysis of the response of Aspergillus niger to ambient $\mathrm{pH}$. Genome Biol. 10.

Arst, H. N., and Penalva, M. A. 2003. pH regulation in Aspergillus and parallels with higher eukaryotic regulatory systems. Trends Genet. 19:224-231.

Arst, H. N., Bignell, E., and Tilburn, J. 1994. 2 New genes involved in signaling ambient $\mathrm{pH}$ in Aspergillus-nidulans. Mol. Gen. Genet. 245:787790

Bauer, S., Gagneur, J., and Robinson, P. N. 2010. GOing Bayesian: Model-based gene set analysis of genome-scale data. Nucleic Acids Res. 38:3523-3532.

Benjamini, Y., and Hochberg, Y. 1995. Controlling the false discovery rate-A practical and powerful approach to multiple testing. J. R. Stat. Soc. Ser. B Methodol. 57:289-300.

Bensen, E. S., Martin, S. J., Li, M. C., Berman, J., and Davis, D. A. 2004. Transcriptional profiling in Candida albicans reveals new adaptive responses to extracellular $\mathrm{pH}$ and functions for Rim101p. Mol. Microbiol. 54:1335-1351.

Bignell, E., Negrete-Urtasun, S., Calcagno, A. M., Haynes, K., Arst, H. N., and Rogers, T. 2005. The Aspergillus $\mathrm{pH}$-responsive transcription factor PacC regulates virulence. Mol. Microbiol. 55:1072-1084.

Brito, N., Espino, J. J., and Gonzalez, C. 2006. The endo-beta-1,4-xylanase xyn11A is required for virulence in Botrytis cinerea. Mol. PlantMicrobe Interact. 19:25-32.

Caddick, M. X., Brownlee, A. G., and Arst, H. N. 1986. Regulation of gene-expression by $\mathrm{pH}$ of the growth-medium in Aspergillus-nidulans. Mol. Gen. Genet. 203:346-353.

Caracuel, Z., Casanova, C., Roncero, M. I., Di Pietro, A., and Ramos, J. 2003a. pH response transcription factor PacC controls salt stress tolerance and expression of the P-Type Na+-ATPase Ena1 in Fusarium oxysporum. Eukaryot. Cell 2:1246-1252.

Caracuel, Z., Roncero, M. I. G., Espeso, E. A., Gonzalez-Verdejo, C. I., Garcia-Maceira, F. I., and Di Pietro, A. 2003b. The pH signalling transcription factor PacC controls virulence in the plant pathogen Fusarium oxysporum. Mol. Microbiol. 48:765-779.

Conesa, A., and Gotz, S. 2008. Blast2GO: A comprehensive suite for functional analysis in plant genomics. Int. J. Plant Genomics 2008:619832.

Darling, A. E., Mau, B., and Perna, N. T. 2010. progressiveMauve: Multi- ple genome alignment with gene gain, loss and rearrangement. PLoS One 5. Published online.

Diaz, J., ten Have, A., and van Kan, J. A. L. 2002. The role of ethylene and wound signaling in resistance of tomato to Botrytis cinerea. Plant Physiol. 129:1341-1351.

Dorn, G. 1965. Phosphatase mutants in Aspergillus nidulans. Science 150:1183-1184.

Eshel, D., Miyara, I., Ailing, T., Dinoor, A., and Prusky, D. 2002. pH regulates endoglucanase expression and virulence of Alternaria alternata persimmon fruit. Mol. Plant-Microbe Interact. 15:774-779.

Espeso, E. A., and Arst, H. N. 2000. On the mechanism by which alkaline $\mathrm{pH}$ prevents expression of an acid-expressed gene. Mol. Cell. Biol. 20:3355-3363.

Espeso, E. A., Tilburn, J., Sanchez-Pulido, L., Brown, C. V., Valencia, A., Arst, H. N., and Penalva, M. A. 1997. Specific DNA recognition by the Aspergillus nidulans three zinc finger transcription factor PacC. J. Mol. Biol. 274:466-480.

Favaron, F., Sella, L., and D’Ovidio, R. 2004. Relationships among endopolygalacturonase, oxalate, $\mathrm{pH}$, and plant polygalacturonase-inhibiting protein (PGIP) in the interaction between Sclerotinia sclerotiorum and soybean. Mol. Plant-Microbe Interact. 17:1402-1409.

Galindo, A., Calcagno-Pizarelli, A. M., Arst, H. N., and Penalva, M. A. 2012. An ordered pathway for the assembly of fungal ESCRT-containing ambient $\mathrm{pH}$ signalling complexes at the plasma membrane. J. Cell Sci. 125:1784-1795.

Gan, P., Ikeda, K., Irieda, H., Narusaka, M., O'Connell, R. J., Narusaka, Y., Takano, Y., Kubo, Y., and Shirasu, K. 2013. Comparative genomic and transcriptomic analyses reveal the hemibiotrophic stage shift of Colletotrichum fungi. New Phytol. 197:1236-1249.

Gourgues, M., Brunet-Simon, A., Lebrun, M. H., and Levis, C. 2004. The tetraspanin BcPls1 is required for appressorium-mediated penetration of Botrytis cinerea into host plant leaves. Mol. Microbiol. 51:619-629.

Horton, P., Park, K. J., Obayashi, T., Fujita, N., Harada, H., Adams-Collier, C. J., and Nakai, K. 2007. WoLF PSORT: Protein localization predictor. Nucleic Acids Res. 35:W585-W587.

Kars, I., Krooshof, G. H., Wagemakers, L., Joosten, R., Benen, J. A. E., and van Kan, J. A. L. 2005. Necrotizing activity of five Botrytis cinerea endopolygalacturonases produced in Pichia pastoris. Plant J. 43:213225.

Kim, Y. K., Wang, Y. H., Liu, Z. M., and Kolattukudy, P. E. 2002. Identification of a hard surface contact-induced gene in Colletotrichum gloeosporioides conidia as a sterol glycosyl transferase, a novel fungal virulence factor. Plant J. 30:177-187.

Kramer-Haimovich, H., Servi, E., Katan, T., Rollins, J., Okon, Y., and Prusky, D. 2006. Effect of ammonia production by Colletotrichum gloeosporioides on pelB activation, pectate lyase secretion, and fruit pathogenicity. Appl. Environ. Microbiol. 72:1034-1039.

Miyara, I., Shafran, H., Haimovich, H. K., Rollins, J., Sherman, A., and Prusky, D. 2008. Multi-factor regulation of pectate lyase secretion by Colletotrichum gloeosporioides pathogenic on avocado fruits. Mol. Plant Pathol. 9:281-291.

Miyara, I., Shafran, H., Davidzon, M., Sherman, A., and Prusky, D. 2010. $\mathrm{pH}$ regulation of ammonia secretion by Colletotrichum gloeosporioides and its effect on appressorium formation and pathogenicity. Mol. PlantMicrobe Interact. 23:304-316.

Miyara, I., Shnaiderman, C., Meng, X., Vargas, W. A., Diaz-Minguez, J. M., Sherman, A., Thon, M., and Prusky, D. 2012. Role of nitrogenmetabolism genes expressed during pathogenicity of the alkalinizing Colletotrichum gloeosporioides and their differential expression in acidifying pathogens. Mol. Plant-Microbe Interact. 25:1251-1263.

Negrete-Urtasun, S., Reiter, W., Diez, E., Denison, S. H., Tilburn, J. Espeso, E. A., Penalva, M. A., and Arst, H. N. 1999. Ambient pH signal transduction in Aspergillus: Completion of gene characterization. Mol. Microbiol. 33:994-1003.

Nilsson, A. I., Koskiniemi, S., Eriksson, S., Kugelberg, E., Hinton, J. C. D., and Andersson, D. I. 2005. Bacterial genome size reduction by experimental evolution. Proc. Natl. Acad. Sci. U.S.A. 102:12112-12116.

O'Connell, R. J., Thon, M. R., Hacquard, S., Amyotte, S. G., Kleemann, J., Torres, M. F., Damm, U., Buiate, E. A., Epstein, L., Alkan, N., Altmuller, J., Alvarado-Balderrama, L., Bauser, C. A., Becker, C., Birren, B. W., Chen, Z. H., Choi, J., Crouch, J. A., Duvick, J. P., Farman, M. A., Gan, P., Heiman, D., Henrissat, B., Howard, R. J., Kabbage, M., Koch, C., Kracher, B., Kubo, Y., Law, A. D., Lebrun, M. H., Lee, Y. H., Miyara, I., Moore, N., Neumann, U., Nordstrom, K., Panaccione, D. G., Panstruga, R., Place, M., Proctor, R. H., Prusky, D., Rech, G., Reinhardt, R., Rollins, J. A., Rounsley, S., Schardl, C. L., Schwartz, D. C., Shenoy, N., Shirasu, K., Sikhakolli, U. R., Stuber, K., Sukno, S. A., Sweigard, J. A., Takano, Y., Takahara, H., Trail, F., van der Does, H. C., Voll, L. M., Will, I., Young, S., Zeng, Q. D., Zhang, J. Z., Zhou, S. G., Dickman, M. B., Schulze-Lefert, P., van Themaat, E. V. L., Ma, L. J., and Vaillancourt, 
L. J. 2012. Lifestyle transitions in plant pathogenic Colletotrichum fungi deciphered by genome and transcriptome analyses. Nat. Genet. 44:10601065.

Opperman, C. H., Bird, D. M., Williamson, V. M., Rokhsar, D. S., Burke, M., Cohn, J., Cromer, J., Diener, S., Gajan, J., Graham, S., Houfek, T. D., Liu, Q., Mitros, T., Schaff, J., Schaffer, R., Scholl, E., Sosinski, B. R., Thomas, V. P., and Windham, E. 2008. Sequence and genetic map of Meloidogyne hapla: A compact nematode genome for plant parasitism. Proc. Natl. Acad. Sci. U.S.A. 105:14802-14807.

Orejas, M., Espeso, E. A., Tilburn, J., Sarkar, S., Arst, H. N., and Penalva, M. A. 1995. Activation of the Aspergillus Pacc transcription factor in response to alkaline ambient $\mathrm{pH}$ requires proteolysis of the carboxyterminal moiety. Genes Dev. 9:1622-1632.

Penalva, M. A., and Arst, H. N. 2002. Regulation of gene expression by ambient $\mathrm{pH}$ in filamentous fungi and yeasts. Microbiol. Mol. Biol. Rev. 66:426-446.

Penalva, M. A., and Arst, H. N. 2004. Recent advances in the characterization of ambient $\mathrm{pH}$ regulation of gene expression in filamentous fungi and yeasts. Annu. Rev. Microbiol. 58:425-451.

Penalva, M. A., Tilburn, J., Bignell, E., and Arst, H. N. 2008. Ambient pH gene regulation in fungi: Making connections. Trends Microbiol. 16:291-300

Prusky, D. 1996. Pathogen quiescence in postharvest diseases. Annu. Rev. Phytopathol. 34:413-434.

Prusky, D., and Yakoby, N. 2003. Pathogenic fungi: Leading or led by ambient pH? Mol. Plant Pathol. 4:509-516.

Prusky, D., McEvoy, J. L., Leverentz, B., and Conway, W. S. 2001. Local modulation of host $\mathrm{pH}$ by Colletotrichum species as a mechanism to increase virulence. Mol. Plant-Microbe Interact. 14:1105-1113.

Prusky, D., McEvoy, J. L., Saftner, R., Conway, W. S., and Jones, R. 2004. Relationship between host acidification and virulence of Penicillium spp. on apple and citrus fruit. Phytopathology 94:44-51.

Prusky, D., Alkan, N., Miyara, I., Barad, S., Davidzon, M., Kobiler, I., Brown-Horowitz, S., Lichter, A., Sherman, A., and Fluhr, R. 2010. Mechanisms modulating postharvest pathogen colonization of decaying fruits. Pages 43-56 in: Postharvest Pathology: Plant Pathology in the 21st Century. D. Prusky and M. L. Gullino. Ninth International Congress. Springer, Dordrecht. The Netherlands.

Rawlings, N. D., Barrett, A. J., and Bateman, A. 2012. MEROPS: The database of proteolytic enzymes, their substrates and inhibitors. Nucleic Acids Res. 40:D343-D350.

Rollins, J. A. 2003. The Sclerotinia sclerotiorum pac1 gene is required for sclerotial development and virulence. Mol. Plant-Microbe Interact. 16:785-795

Rollins, J. A., and Dickman, M. B. 2001. PH signaling in Sclerotinia sclerotiorum: Identification of a pacC/RIM1 homolog. Appl. Environ. Microbiol. 67:75-81.

Selvig, K., and Alspaugh, J. A. 2011. pH response pathways in fungi: Adapting to host-derived and environmental signals. Mycobiology 39:249-256

Shafran, H., Miyara, I., Eshed, R., Prusky, D., and Sherman, A. 2008. Development of new tools for studying gene function in fungi based on the Gateway system. Fungal Genet. Biol. 45:1147-1154.

Shnaiderman, C., Miyara, I., Kobiler, I., Sherman, A., and Prusky, D. 2013. Differential activation of ammonium transporters during the accumulation of ammonia by Colletotrichum gloeosporioides and its Effect on appressoria formation and pathogenicity. Mol. Plant-Microbe Interact. 26:345-355

Siewers, V., Viaud, M., Jimenez-Teja, D., Collado, I. G., Gronover, C. S. Pradier, J. M., Tudzynski, B., and Tudzynski, P. 2005. Functional analysis of the cytochrome P450 monooxygenase gene bcbot1 of Botrytis cinerea indicates that botrydial is a strain-specific virulence factor. Mol. Plant-Microbe Interact. 18:602-612.

Soderlund, C., Nelson, W., Shoemaker, A., and Paterson, A. 2006. SyMAP: A system for discovering and viewing syntenic regions of FPC maps. Genome Res. 16:1159-1168.

Soulie, M. C., Piffeteau, A., Choquer, M., Boccara, M., and Vidal-Cros, A 2003. Disruption of Botrytis cinerea class I chitin synthase gene Bcchs 1 results in cell wall weakening and reduced virulence. Fungal Genet. Biol. 40:38-46.

Staats, M., van Baarlen, P., and van Kan, J. A. L. 2005. Molecular phylogeny of the plant pathogenic genus Botrytis and the evolution of host specificity. Mol. Biol. Evol. 22:333-346.

ten Have, A., Mulder, W., Visser, J., and van Kan, J. A. L. 1998. The endopolygalacturonase gene Bcpg1 is required for full virulence of Botry tis cinerea. Mol. Plant-Microbe Interact. 11:1009-1016.

Ter-Hovhannisyan, V., Lomsadze, A., Chernoff, Y. O., and Borodovsky, M. 2008. Gene prediction in novel fungal genomes using an ab initio algorithm with unsupervised training. Genome Res. 18:1979-1990.

Tilburn, J., Sarkar, S., Widdick, D. A., Espeso, E. A., Orejas, M., Mungroo, J., Penalva, M. A., and Arst, H. N. 1995. The Aspergillus Pacc zinc-finger transcription factor mediates regulation of both acidexpressed and alkaline-expressed genes by ambient pH. EMBO (Eur. Mol. Biol. Organ.) J. 14:779-790.

Trapnell, C., Pachter, L., and Salzberg, S. L. 2009. TopHat: Discovering splice junctions with RNA-Seq. Bioinformatics 25:1105-1111.

Tu, J. C. 1985. An improved Mathur medium for growth, sporulation, and germination of spores of Colletotrichum-lindemuthianum. Microbios 44:87-93

Valette-Collet, O., Cimerman, A., Reignault, P., Levis, C., and Boccara, M. 2003. Disruption of Botrytis cinerea pectin methylesterase gene Bcpme1 reduces virulence on several host plants. Mol. Plant-Microbe Interact. 16:360-367.

van Dongen, S. 2000. Graph Clustering by Flow Simulation. University of Utrecht, Utrecht, The Netherlands.

Weir, B. S., Johnston, P. R., and Damm, U. 2012. The Colletotrichum gloeosporioides species complex. Stud. Mycol. 73:115-180.

Wharton, P. S., and Diéguez-Uribeondo, J. 2004. The biology of Colletotrichum acutatum. An. Jardìn Bot. Madrid 61:3-22.

Wubben, J. P., ten Have, A., van Kan, J. A. L., and Visser, J. 2000. Regulation of endopolygalacturonase gene expression in Botrytis cinerea by galacturonic acid, ambient $\mathrm{pH}$ and carbon catabolite repression. Curr. Genet. 37:152-157.

Yakoby, N., Kobiler, I., Dinoor, A., and Prusky, D. 2000. pH regulation of pectate lyase secretion modulates the attack of Colletotrichum gloeosporioides on avocado fruits. Appl. Environ. Microbiol. 66:1026-1030.

Yakoby, N., Beno-Moualem, D., Keen, N. T., Dinoor, A., Pines, O., and Prusky, D. 2001. Colletotrichum gloeosporioides pelB is an important virulence factor in avocado fruit-fungus interaction. Mol. Plant-Microbe Interact. 14:988-995

You, B. J., Choquer, M., and Chung, K. R. 2007. The Colletotrichum acutatum gene encoding a putative $\mathrm{pH}$-responsive transcription regulator is a key virulence determinant during fungal pathogenesis on citrus. Mol. Plant-Microbe Interact. 20:1149-1160.

\section{AUTHOR-RECOMMENDED INTERNET RESOURCES}

Blast2GO software website: www.blast2go.com/b2ghome

Joint Genome Institute, Glomerata cingulata 23 webpage: genome.jgi.doe.gov/Gloci1/Gloci1.home.html

KEGG PATHWAY database: www.genome.jp/kegg/pathway.html 